\title{
2010s-24
}

\section{Heterogeneous Treatment and Self-Selection in a Wage Subsidy Experiment}

\author{
Dany Brouillette, Guy Lacroix
}

Série Scientifique
Scientific Series

\begin{abstract}
Montréal
Mai 2010
\end{abstract}

(C) 2010 Dany Brouillette, Guy Lacroix. Tous droits réservés. All rights reserved. Reproduction partielle permise avec citation du document source, incluant la notice ().

Short sections may be quoted without explicit permission, if full credit, including $@$ notice, is given to the source.
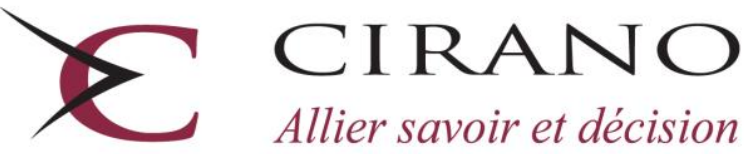

Allier savoir et décision

Centre interuniversitaire de recherche en analyse des organisations 


\section{CIRANO}

Le CIRANO est un organisme sans but lucratif constitué en vertu de la Loi des compagnies du Québec. Le financement de son infrastructure et de ses activités de recherche provient des cotisations de ses organisations-membres, d'une subvention d'infrastructure du Ministère du Développement économique et régional et de la Recherche, de même que des subventions et mandats obtenus par ses équipes de recherche.

CIRANO is a private non-profit organization incorporated under the Québec Companies Act. Its infrastructure and research activities are funded through fees paid by member organizations, an infrastructure grant from the Ministère du Développement économique et régional et de la Recherche, and grants and research mandates obtained by its research teams.

\section{Les partenaires du CIRANO}

Partenaire majeur

Ministère du Développement économique, de l'Innovation et de l'Exportation

\section{Partenaires corporatifs}

Banque de développement du Canada

Banque du Canada

Banque Laurentienne du Canada

Banque Nationale du Canada

Banque Royale du Canada

Banque Scotia

Bell Canada

BMO Groupe financier

Caisse de dépôt et placement du Québec

Fédération des caisses Desjardins du Québec

Gaz Métro

Hydro-Québec

Industrie Canada

Investissements PSP

Ministère des Finances du Québec

Power Corporation du Canada

Raymond Chabot Grant Thornton

Rio Tinto

State Street Global Advisors

Transat A.T.

Ville de Montréal

\section{Partenaires universitaires}

École Polytechnique de Montréal

HEC Montréal

McGill University

Université Concordia

Université de Montréal

Université de Sherbrooke

Université du Québec

Université du Québec à Montréal

Université Laval

Le CIRANO collabore avec de nombreux centres et chaires de recherche universitaires dont on peut consulter la liste sur son site web.

Les cahiers de la série scientifique (CS) visent à rendre accessibles des résultats de recherche effectuée au CIRANO afin de susciter échanges et commentaires. Ces cahiers sont écrits dans le style des publications scientifiques. Les idées et les opinions émises sont sous l'unique responsabilité des auteurs et ne représentent pas nécessairement les positions du CIRANO ou de ses partenaires.

This paper presents research carried out at CIRANO and aims at encouraging discussion and comment. The observations and viewpoints expressed are the sole responsibility of the authors. They do not necessarily represent positions of CIRANO or its partners. 


\title{
Heterogeneous Treatment and Self-Selection in a Wage Subsidy Experiment ${ }^{*}$
}

\author{
Dany Brouillette ${ }^{\dagger}$, Guy Lacroix
}

\begin{abstract}
Résumé / Abstract
Le Projet d'autosuffisance (PAS) est une initiative de recherche et de démonstration destinée à offrir un généreux supplément de revenu temporaire aux demandeurs de l'aide sociale recrutés au hasard, moyennant deux conditions. La première, soit l'admissibilité, exigeait que les personnes retenues touchent l'aide sociale pendant une période minimale de 12 mois. La seconde, c'est-àdire la qualification, exigeait qu'elles trouvent un emploi à temps plein dans les 12 mois suivant l'établissement de leur admissibilité. Dans le présent document, nous mettons l'accent sur une caractéristique du programme, à la fois importante et négligée, à savoir que la récompense financière associée au fait de se qualifier est inversement liée au taux de rémunération espéré. Sur la base d'hypothèses très simples, nous montrons que les personnes dont le taux de rémunération espéré est faible sont clairement incitées à établir leur admissibilité. L'évidence empirique non paramétrique laisse fortement à penser que les personnes s'autosélectionnent dans la démarche d'admissibilité. Nous évaluons conjointement une équation de participation et une équation de rémunération, corrélées par des effets aléatoires individuels. Nos résultats indiquent que l'omission du facteur d'autosélection lié à la qualification se traduit par des effets légèrement sous-estimés sur le traitement.
\end{abstract}

Mots clés : Étude sur les candidats du PAS, traitement hétérogène, autosélection.

The Self-Sufficiency Project (SSP) is a research and demonstration project that offered a generous time-limited income supplement to randomly selected welfare applicants under two conditions. The first, the eligibility condition, required that they remain on welfare for at least twelve months. The second, the qualification condition, required that they find a full-time job within twelve months after establishing eligibility. In this paper, we focus on a neglected and important feature of the program, namely that the financial reward for becoming qualified is inversely related to the expected wage rate. Under very simple assumptions we show that those who have a low expected wage rate have a clear incentive to establish eligibility. Empirical nonparametric evidence strongly suggests that individuals self-select into eligibility. We jointly estimate a participation equation and a wage equation that are correlated through individual random effects. Our results show that the omission of selfselectivity into qualification translates into slightly underestimated treatment effects.

Keywords: SSP Applicant Study, heterogeneous treatment, self-selection.

Codes JEL : I38, J31, J64

\footnotetext{
* We are grateful to SRDC for research support and for making the SSP data available, and to Douglas Tattrie for assistance with the data. We also thank the editor and an anonymous referee for comments. The conclusions in this paper are the sole responsibility of the authors, and do not represent the opinions or conclusions of SRDC, the sponsors of the Self Sufficiency Project, Industry Canada or the Government of Canada.

${ }^{\dagger}$ Industry Canada.

† CIRPÉE, IZA, Université Laval, email: Guy.Lacroix@ecn.ulaval.ca.
} 


\section{Introduction}

The Self-Sufficiency Project (SSP) includes various demonstrations that were conducted in Canada to measure the sensitivity of behavioural adjustments to various income support schemes. One of the demonstrations, the Applicant Demonstration Project, offered a generous three-year income supplement to randomly selected welfare applicants under two important conditions. The first, the eligibility condition, required that they remained on welfare for at least twelve months to become eligible for the supplement. The second, the qualification condition, required that they find a full-time job and left the rolls within twelve months after establishing eligibility. Applicants randomly assigned to the control group were entitled to the regular IA program. One of the objectives of the Applicant demonstration was to measure the so-called "delayed exit" effect, that is the extent to which welfare applicants might delay their exit from $I A$ in order to establish eligibility. Although a number of studies have found evidence of delayed exit behavior, all agree that the effect is small [Card and Robins (2005), Berlin, Bancroft, Card, Lin and Robins (1998), Kamionka and Lacroix (2009)].

The main benefit of randomized social experiments is to guarantee homogeneity between control and treatment groups in terms of observable and unobservable characteristics. Yet, it does not prevent self-selection into the various phases of the experiment or across employment/nonemployment. These problems have been acknowledged for some time [e.g. Dubin and Rivers (1993) and Ham and LaLonde (1996)in different contexts]. In a recent paper, Card and Hyslop (2009) use a dynamic discrete choice model of $I A$ participation to separate total SSP effect into three different effects: (1) an incentive to remain on $I A$ to gain eligibility; (2) an incentive to work in the qualification phase; (3) an incentive to choose work over $I A$ in the SSP phase in order to receive the supplement. Their results show strong responses to all three incentives. They found that about two-thirds of the total SSP effect was due to short-term incentives (qualification effect). ${ }^{1}$ It is thus very likely that the subset of applicants who establish eligibility may be a self-selected group. Likewise, conditional on establishing eligibility, those who manage to qualify for the supplement may constitute yet another self-selected group. ${ }^{2}$

In this paper we focus on one important and neglected feature of the SSP program, namely that the financial reward for establishing qualification is inversely related to the expected wage rate. Thus, contrary to the aforementioned papers, we acknowledge the fact that the "treatment" is not homogeneous but is a continuum that depends on observable (human capital) and unobservable (heterogeneity) characteristics. In the most extreme case, an individual in the treatment group may deem the income supplement as irrelevant because of her high expected wage rate. Under very simple assumptions about the wage offer distribution, we show

\footnotetext{
${ }^{1}$ Based on the Recipient Demonstration, Zabel, Schwartz and Donald (2004) have found similar results, although receipt of the income supplement was found to have had a negative impact on the probability of exiting unemployment once entitlement ended.

${ }^{2}$ In a recent paper which focuses on the Recipient demonstration, Bitler, Gelbach and Hoynes (2006) provide empirical evidence that high-earning treatments may be willing to accept lower-paying jobs in order to qualify for the supplement.
} 
that those who establish eligibility are probably a self-selected group with lower than average wage rates. Under these assumptions, we show that the impact of the financial reward on employment are likely overestimated. We provide non-parametric evidence to the effect that individuals in the treatment group self-select into different statuses. Those who do not establish eligibility (i.e. exit $I A$ within twelve months after random assignment) earn the highest average wage rate. Irrespective of their qualification status, those who establish eligibility earn the lowest wage rates.

We investigate the impact of the SSP supplement using a gradual approach. First, we model the transitions between $I A$ and employment using a simple random effects probit model. The treatment and control groups are distinguished by a series of time-varying dummy variables. Because the eligibility and qualification statuses are not modelled explicitly, the parameter estimates are similar to the so-called average treatment effects. In order measure the impact of SSP on those who qualified, we next estimate a similar probit model but explicitly model the eligibility and qualification statuses. The parameter estimates are similar to the so-called average treatment on the treated effects. This model is contrasted with a specification that allows for selection into qualification by jointly estimates the transition model and the accepted wage rates. Both equations are correlated through their random effects and contemporaneous error terms. In the absence of self-selection into the eligibility and qualification statuses, both models should yield the same results. It turns out that accounting for the potential correlation between the wage equation and the transition model increases slightly the estimated impact of the SSP treatment.

The paper is organized as follows. Section 2 briefly presents the SSP Applicant Demonstration and proposes a simple structural model with the necessary assumptions to give rise to self-selection into eligibility. Section 3 provides simple descriptive statistics and non-parametric evidence on potential selectivity problems. In Section 4 we propose an econometric model that attempts to circumvent the selection issues and whose results are presented in Section 5. Finally, we conclude the paper in Section 6.

\section{The Applicant Demonstration}

One of the objectives of the Applicant Demonstration was to measure the delayed exit effect associated with being offered a generous wage subsidy conditional on remaining on the welfare rolls for a minimum of 13 months. It randomly sampled single parents who had applied for and received income assistance between February 1994 and February 1995 in British Columbia. ${ }^{3}$ The program offered a generous, time-limited, monthly cash payment to all those who found full-time job and left welfare within twelve months after meeting the eligibility requirement. The program is composed of three phases, as illustrated in Figure 1.

\footnotetext{
${ }^{3}$ To be considered as new entrants, applicants had not to have received $I A$ in the six previous months. A significant minority $(31 \%)$ had nevertheless received $I A$ at some time in the two years prior to their current application (Berlin et al. (1998)).
} 
Figure 1: Phases of the Applicant Demonstration

\begin{tabular}{|c|c|c|c|}
\hline $\begin{array}{c}\text { Eligibility } \\
\text { Phase }\end{array}$ & $\begin{array}{c}\text { Qualification } \\
\text { Phase }\end{array}$ & $\begin{array}{l}\text { Entitlement } \\
\text { (SSP) Phase }\end{array}$ & $\begin{array}{c}\text { Post SSP } \\
\text { Phase }\end{array}$ \\
\hline & & & \\
\hline & & & \\
\hline
\end{tabular}

Time since random assignment

The 13-month eligibility phase is the time treatments must remain on the $I A$ rolls to be eligible for potential SSP payments $\left(T_{1}=13\right)$. Failure to meet the requirement automatically entails disqualification. ${ }^{4}$ The qualification phase lasts a maximum of 12 months $\left(T_{2} \leq 25\right)$. During that period, eligible treatments must find a full-time job (at least 30 hours/week) and leave the rolls. Failure to find a job disqualifies them for SSP benefits. The entitlement phase starts immediately upon qualification (at month 25 at the latest) and lasts 36 months $\left(T_{3} \leq 61\right)$. During that period, qualified treatment earn a monthly subsidy if employed and are allowed to switch back and forth between employment and $I A$ without losing their entitlement.

Over the course of the entitlement (SSP) phase, the subsidy is paid out each month based on the estimated annual earnings. The subsidy is equivalent to $S(w, h)=50 \% \times(37,500 \$-w h)$, where $w$ is the hourly wage rate and $h$ is the annual hours of work. The subsidy can be relatively large. ${ }^{5}$ For example, an individual working 35 hours a week at $7 \$$ per hour would have a gross earning of $12,740 \$$ per year without SSP and $25,183 \$$ with SSP. ${ }^{6}$ It must be noted that the distribution of the supplement is highly skewed. Qualified treatments in the upper quartile of the distribution received on average 32,394\$ over the SSP phase, while those in the lower quartile only received 6,145\$ [Ford, Gyarmati, Foley, Tattrie and Jimenez (2003)].

As underlined above, the Applicant study features three different phases: Eligibility, Qualification, and Entitlement. The manner in which the phases are structured gives rise to complex incentives. To gain better understanding, a number of authors have turned to standard search models à la Mortensen (1977) to investigate potential individual responses [See, e.g., Card and Hyslop (2005),Card and Hyslop (2009) and Bowlus et al. (2006)]. In what follows, we briefly sketch a simple search model and underline how potential self-selection into the eligibility phase may arise.

\footnotetext{
${ }^{4}$ In fact, welfare recipients had to be on the rolls 12 out of the first 13 months after randomization. In this paper, we define eligibility as being on welfare for 13 out of the first 13 months after random assignment.

${ }^{5}$ The benchmark earnings was adjusted to account for increases in the cost of living and was set at $37,625 \$$ in 1996.

${ }^{6}$ Bowlus, Lochner, Robinson and Zhong (2006) have argued that the subsidy was in fact too generous. Using a structural search model with human capital, they find that lowering the benchmark earnings from $37,500 \$$ to $24,000 \$$ would have yielded the same results.
} 


\subsection{The problem of the control group}

Start first with individuals in the control group. Assume they are risk-neutral and have to choose between employment $(E)$ and income assistance $(I A)$, which, for simplicity, are assumed to be mutually exclusive states. Workers and welfare recipients receive job offers at a constant rate, $\lambda$, that are characterized by a wage offer, $\omega$, drawn from a stationary distribution, $F(\omega)$, with $\omega \in[\underline{\omega}, \bar{\omega}]$. The net payoff is equal to $\omega-c$, where $c$ represents fixed costs to work. Income assistance provides a monthly benefit equal to $b$. Individuals are assumed to maximize expected future income using a monthly discount rate, $r$. The utility derived from the job offer is compared to the utility derived from welfare. In addition, workers face an exogenous probability of losing their job, $\delta$ (job destruction rate).

Individuals are assumed to follow a reservation-wage strategy. They will reject any wage offer below their reservation wage. Workers will refuse any offer worth less than their current wage. To see this, let $\omega^{r}$ be the reservation wage. The expected steady-state inter-temporal utility of $I A$ is given by:

$$
(1+r) V^{I A}=b+\lambda \int_{\omega^{r}}^{\bar{\omega}} V^{E}(\omega) d F(\omega)+\left[1-\lambda\left(1-F\left(\omega^{r}\right)\right)\right] V^{I A},
$$

where $V^{E}(\omega)$ is the value of a job paying $\omega$. The last term on the right-hand side is the value of $I A$ assuming no satisfactory job offer was received. The value function of employed individuals is equal to:

$$
(1+r) V^{E}(\omega)=(\omega-c)+\lambda \int_{\omega}^{\bar{\omega}} V^{E}(\tilde{\omega}) d F(\tilde{\omega})+\delta V^{I A}+[1-\delta-\lambda(1-F(\omega))] V^{E}(\omega) .
$$

The first term on the right-hand side is the net income from a job paying $\omega$. The second term is the marginal benefit accruing from a job offer that exceeds the current wage. The third term corresponds to the expected value of $I A$ due to a job loss. Finally the last expression corresponds to the value of remaining on the same job because no satisfactory offer was received.

The reservation wage is such that $V^{E}\left(\omega^{r}\right)=V^{I A}$. By substitution, it thus follows that $\omega^{r}=b+c$. In other words, an individual will always refuse a job offer that does not entirely compensate $I A$ benefits, $b$, and fixed costs, $c$. This results is fairly common and follows from the fact that the environment in which the individual must make decisions is in steady-state.

\subsection{The problem of the treatment group}

Contrary to the control group, the treatment group faces a non-stationary environment. Consequently, decisions are contingent upon time and must be analyzed separately for each SSPphase.

- Phase 1: Eligibility

Phase 1 lasts $T_{1}=13$ months. Over the course of the phase individuals must compare 
the value of $I A$ conditional on not having left $I A$ once and becoming potentially qualified in Phase 2, with that of taking a job and losing eligibility. Let $V_{t}^{I A, 1}$ denote the value of $I A$ at month $t$ in Phase 1. The value functions prior to establishing eligibility are:

$$
(1+r) V_{t}^{I A, 1}= \begin{cases}b+\lambda \int_{\omega_{t}^{r, 1}}^{\bar{\omega}} V^{E}(\omega) d F(\omega)+\left[1-\lambda\left(1-F\left(\omega_{t}^{r, 1}\right)\right)\right] V_{t+1}^{I A, 1} & \text { if } t \leq T_{1}-2 \\ b+\lambda \int_{\omega_{t}^{r, 1}}^{\omega} V^{E}(\omega) d F(\omega)+\left[1-\lambda\left(1-F\left(\omega_{t}^{r, 1}\right)\right)\right] V_{1}^{I A, 2} & \text { if } t=T_{1}-1,\end{cases}
$$

where $\omega_{t}^{r, 1}$ is the reservation wage at month $t$ of Phase 1 , and where $V_{1}^{I A, 2}$ is the value of $I A$ in the first month of Phase 2. Each month $t \leq T_{1}-1$ the individual must decide whether she will accept a job starting at the beginning of next month. Acceptance is akin to refusing future SSP benefits and facing the control group's problem. The value of the job must be compared to the value of remaining an additional month on $I A$ and increasing the likelihood of establishing eligibility.

At month $T_{1}$ those who find employment starting at month $T_{1}+1$ are automatically entitled to the SSP benefit. Thus at month $T_{1}-1$ the appropriate continuation value is $V_{1}^{I A, 2}$, the value of $I A$ at the beginning of Phase 2, conditional on not yet being qualified.

The reservation wage in Phase 1 is implicitly given by:

$$
V^{E}\left(\omega_{t}^{r, 1}\right)= \begin{cases}V_{t+1}^{I A, 1} & \text { if } t \leq T_{1}-2 \\ V_{1}^{I A, 2} & \text { if } t=T_{1}-1\end{cases}
$$

- Phase 2: Qualification

Having established eligibility, individuals must find a full-time job within 12 months in order to qualify for SSP benefits. Prior to qualifying, the value functions are given by:

$$
(1+r) V_{t}^{I A, 2}= \begin{cases}b+\lambda \int_{\omega_{t}^{r, 2}}^{\bar{\omega}} W^{E}(\omega, 1) d F(\omega)+\left[1-\lambda\left(1-F\left(\omega_{t}^{r, 2}\right)\right)\right] V_{t+1}^{I A, 2} & \text { if } t \leq T_{2}-1 \\ b+\lambda \int_{\omega_{t}^{r, 2}}^{\omega} V^{E}(\omega) d F(\omega)+\left[1-\lambda\left(1-F\left(\omega_{t}^{r, 2}\right)\right)\right] V^{I A} & \text { if } t=T_{2} .\end{cases}
$$

Here $W^{E}(\omega, 1)$ is the value function of employed individuals receiving a wage $\omega$ with one month of elapsed benefits. Thus each month $t \leq T_{2}-1$ the individual must compare the value of a job worth $W^{E}(\omega, 1)$ with the value of postponing employment an additional month $\left(V_{t+1}^{I A, 2}\right)$. Past the qualification period, i.e. at $t=T_{2}$, the individual faces the control group's problem and the environment becomes stationary (hence the omission of time indicators on the value function $V^{I A}$ ).

The reservation wage in Phase 2 is implicitly given by:

$$
W^{E}\left(\omega_{t}^{r, 2}, 1\right)=V_{t+1}^{I A, 2} \quad \text { if } 1 \leq t \leq T_{2}-1
$$

- Phase 3: Entitlement

Treatments who have qualified for the supplement are entitled to $T_{3}=36$ months of benefits. The value functions for being on $I A$ are given by:

$$
(1+r) V_{t}^{I A, 3}= \begin{cases}b+\lambda \int_{\omega_{t}^{r, 3}}^{\bar{\omega}} W^{E}(\omega, t+1) d F(\omega)+\left[1-\lambda\left(1-F\left(\omega_{t}^{r, 3}\right)\right)\right] V_{t+1}^{I A, 3} & \text { if } 2 \leq t \leq T_{3}-1 \\ b+\lambda \int_{\omega_{t}^{r, 3}}^{\bar{\omega}} V^{E}(\omega) d F(\omega)+\left[1-\lambda\left(1-F\left(\omega^{r}\right)\right)\right] V^{I A} & \text { if } t=T_{3}\end{cases}
$$


At $t=T_{3}$, the entitlement period ends and the treatment now faces the same problem a control does. The reservation wage in Phase 3 is implicitly given by:

$$
W^{E}\left(\omega_{t}^{r, 3}, t+1\right)=V_{t+1}^{I A, 3} \quad \text { if } 2 \leq t \leq T_{3}-1
$$

The reservation wage profile can be easily derived from the above value functions. Note first that $W^{E}(\omega, 1)>V^{E}(\omega)$, i.e. a Phase 2 job with SSP benefits is worth more than a job that does not carry a bonus. It thus follows that $V_{1}^{I A, 2}>V^{I A}$ and that $V_{t+1}^{I A, 1}>V_{t}^{I A, 1}$. Hence the reservation wage increases as the end of Phase 1 approaches, i.e. $\omega_{t}^{r, 1}<\omega_{t+1}^{r, 1}$. It can also be shown that $\omega_{T_{1}}^{r, 1}>\omega^{r}$ due to the fact that $V_{1}^{I A, 2}>V^{I A}$. Thus the reservation wage increases as one nears $T_{1}$ and is necessarily higher than that of the control group at $T_{1}$. Treatments are thus expected to have lower exit rates in Phase 1 (delayed exit effect).

The same type of reasoning applies to Phase 2. Indeed, because $W^{E}(\omega, 1)>V^{E}(\omega)$, it follows that $V_{1}^{I A, 2}>V^{I A}$ and $V_{t+1}^{I A, 2}<V_{t}^{I A, 2}$. In other words, access to potential benefits increases the value of $I A$ at the beginning of Phase 2. It declines regularly as one nears $T_{2}$ due to the potential loss of SSP benefits. Because $W^{E}(\omega, 1)$ increases with $\omega$, this is equivalent to $\omega_{t}^{r, 2}>\omega_{t+1}^{r, 2}$, i.e. the reservation wage declines with $t$. In Phase 3 it can also be shown that the reservation wage is constant throughout. In addition, because $V_{T_{3}}^{I A}=V^{I A}$ it follows that $\omega_{T_{3}}^{r, 3}=\omega^{r}$. Finally, because $W^{E}\left(\omega, T_{3}\right)>V^{E}(\omega)$ it must be the case that prior to $T_{3}$, $\omega_{T_{3}-t}^{r, 3}<\omega^{r}$. Treatments are thus expected to have higher transition rates into employment.

\subsection{Selection into eligibility}

The analysis so far has assumed that individuals receive wage offers that are drawn from a single distribution. As stressed by Stern and Canals-Cerda (2002), unobserved characteristics are important in explaining the behavior of workers in the labor market. For example, workers with identical observed characteristics may face different wage offer distributions and have different reservation wages due to differences in relevant unobserved characteristics. Unfortunately, very few analyzes have considered unobserved heterogeneity within the context of a search model. This is particularly important in the context of the SSP program since the incentive effects are directly proportional to the wage rate a worker is likely to receive.

Recently, a number of authors have introduced heterogeneity both on the supply side (workers) and the demand side (firms) of equilibrium search models [see Bontemps, Robin and den Berg (1999), Postel-Vinay and Robin (2002)]. Others have introduced preference heterogeneity within a partial-equilibrium model [e.g. Bloemen (1997)]. To illustrate how potential selection problems into eligibility may arise, we now assume that the wage offer distribution depends on some unobserved heterogeneity component, $\varepsilon$, that is drawn from a distribution with mean 0 and finite variance. We may consider $\varepsilon$ as a productivity factor that is unobserved by the analyst but known to the individual (and valued by the market). For convenience, we may write the conditional wage distribution as $F(\omega \mid \varepsilon)$. 
To fix ideas, we assume as in Bowlus et al. (2006) that workers have different (unobservable) skills and receive a wage equal to $\tilde{\omega}=\omega+\varepsilon .{ }^{7}$ The unobservable component, $\varepsilon$, is assumed continuously distributed over $[\underline{\varepsilon}, \bar{\varepsilon}]$. The above discussion has made clear that the differences between the control and the treatment groups' reservation wage profiles hinge on the value of the SSP benefits in Phase 3. The value of a Phase 3 job may be written as follows:

$$
\begin{aligned}
(1+r) W^{E}(\tilde{\omega}, t)= & (\omega+\varepsilon-c)+\frac{S S P_{t}-\omega-\varepsilon}{2}+\lambda \int_{\tilde{\omega}}^{\bar{\omega}} W^{E}\left(\omega^{\prime}, t+1\right) d F\left(\omega^{\prime}\right) \\
& +\delta V_{t+1}^{I A, 3}+[1-\delta-\lambda(1-F(\tilde{\omega}))] W^{E}(\tilde{\omega}, t+1),
\end{aligned}
$$

where $\left(S S P_{t}-\omega-\varepsilon\right) / 2$ represents the net SSP benefit. Obviously, individuals with large values of $\varepsilon$ will receive a large wage offer soon after randomization. Consequently they will expect relatively low SSP benefits. For them the incentive to postpone exit from welfare in Phase 1 is much smaller. In fact, there might exist a critical value, $\varepsilon^{*} \in[\underline{\varepsilon}, \bar{\varepsilon}]$, such that $W^{E}\left(\varepsilon^{*}, 1\right)=V^{E}(\omega)$, i.e the net SSP benefit is zero. Individuals in the treatment group with $\varepsilon \geq \varepsilon^{*}$ thus behave no differently from those in the control group. In addition, because they typically command a greater than average wage rate, they can be expected to leave $I A$ at a higher rate than controls. Likewise, one may also argue that the entitlement effect in Phase 3 will be larger the smaller the (expected) wage offer. Indeed, individuals who expect low wage offers benefit on average from a relatively large subsidy. The converse naturally holds for those who receive high wage offers. It is thus difficult to distinguish the entitlement effect from the unobserved heterogeneity component in Phase 3. The problem may even be compounded if we allowed for unobserved preference heterogeneity as in Bloemen (1997) and Wolpin and Eckstein (1989).

The above discussion underlines the potential for selectivity into eligibility due to the builtin SSP incentives. Hence, the treatment group can be divided into three subgroups: those who do not establish eligibility, those who establish eligibility but do not manage to qualify and those who qualify, conditional on establishing eligibility. The main issue from a statistical point of view is to determine the distribution of $\varepsilon$ among the different subgroups. To the extent the distribution is the same across the subgroups, a simple comparison between those who qualify and the control group would provide an unbiased estimator of the treatment effect on the treated. The above discussion suggest this is rather unlikely. In the next section we provide prima facie evidence on potential self-selectivity into eligibility.

\section{Data}

The data we use in this paper are drawn from the SSP Applicant Study. Selected individuals who agreed to be part of the experiment were interviewed at home to complete a baseline

\footnotetext{
${ }^{7}$ Alternatively, we could assume as suggested by Stern and Canals-Cerda (2002) that individuals face different wage offer distributions. We could write $F\left(\omega ; m_{i}, \tau_{i}\right)$ where $m_{i}$ is the location parameter of group or individual $i$, and $\tau_{i}$ is the dispersion parameter.
} 
survey. They were asked to sign an informed consent document that explained the nature of the experiment, described the random assignment process, and stated that all individual-level data would be kept confidential. They also had to agree to have their administrative social assistance record linked to the survey data. Immediately after the baseline interview, individuals were randomly assigned to either the treatment or the control group. The experimental sample comprises 1,648 treatments and 1,667 controls. Treatments were sent a letter and a brochure explaining their potential eligibility for an earnings supplement. They were reminded they had to remain on welfare for at least 12 months to be eligible for the supplement, and that upon establishing eligibility, they had to find a full-time job within the next 12 months to qualify for the income supplement. ${ }^{8}$

Four follow-up surveys were conducted 12, 30, 48 and 72 months after the baseline interview to keep track of changes in educational attainment, work-related training, employment, work experience, marital status, number of children, etc. Information on $I A$ benefits per se was obtained from administrative records. Due to sample attrition, of the 3,315 original respondents in the baseline interview, only 2,015 completed all succeeding follow-up interviews. The analysis in this paper is based on this balanced panel. ${ }^{9}$

\subsection{Sample statistics}

Table 1 presents descriptive statistics for our sample at baseline. The first and second columns concern the control group and the treatment group as a whole. In columns (3)-(5) the treatment group is broken down into those who are unqualified, ineligible and qualified. Unqualified applicants have established eligibility but did not find a job in the qualification phase, while ineligible applicants left $I A$ within 13 months and have not established eligibility. ${ }^{10}$ Qualified applicants have established eligibility and did find a job during the qualification phase. Despite having removed nearly $40 \%$ of the original sample, columns (1) and (2) show that control and treatment groups are nearly identical. ${ }^{11}$ Thus attrition is unlikely to affect a particular group of applicants. ${ }^{12}$ The figures show that the mean age is about 33, that women represent about 93\% of all applicants, that approximately $71 \%$ were born in Canada, and that very few had a spouse at baseline. Individuals in the sample are relatively well educated. Indeed, over $68 \%$

\footnotetext{
${ }^{8}$ Although SSP rules stated that qualification had to occur between months 13 and 24 after random assignment, these were interpreted rather loosely. In the data, individuals have qualified as early as month 11 and as late as month 27.

${ }^{9}$ We also imposed a few additional restrictions. For instance one applicant reported a negative age and 47 did not report years of experience properly. Upon deleting these 48 observations we are left with a sample of 1,967 applicants who are each observed for 71 consecutive months.

${ }^{10}$ Recall that we define eligibility as remaining on $I A$ for the first 13 months after random assignment.

${ }^{11}$ Although not reported, we tested that the means of each variable in Table 1 was identical for the two groups. The null assumption was never rejected.

${ }^{12}$ See Hansen (2006) for a detailed analysis of the sample attrition in the SSP Applicant study.
} 
of them had either attended a community college or a university. Finally, roughly $41 \%$ own a car but very few own a house. ${ }^{13}$

Table 1: Sample statistics: Mean individual characteristics at baseline

\begin{tabular}{|c|c|c|c|c|c|}
\hline & Control group & & Treatr & group & \\
\hline & & All & Unqualified & Ineligible & Qualified \\
\hline & $(1)$ & $(2)$ & $(3)$ & $(4)$ & $(5)$ \\
\hline \multirow[t]{2}{*}{ Gender $($ woman $=1)$} & 0.93 & 0.92 & 0.94 & 0.91 & 0.92 \\
\hline & $(0.25)$ & $(0.27)$ & $(0.24)$ & $(0.28)$ & $(0.27)$ \\
\hline \multirow[t]{2}{*}{ Age (years) } & 33.23 & 33.41 & 33.30 & 33.99 & 32.63 \\
\hline & $(7.20)$ & $(7.80)$ & $(7.35)$ & $(8.25)$ & $(7.40)$ \\
\hline \multirow{2}{*}{ Married $($ married $=1)$} & 0.06 & 0.07 & 0.04 & 0.09 & 0.05 \\
\hline & $(0.23)$ & $(0.25)$ & $(0.19)$ & $(0.29)$ & $(0.23)$ \\
\hline \multirow[t]{2}{*}{ Born $($ Canada = 1) } & 0.72 & 0.70 & 0.60 & 0.75 & 0.73 \\
\hline & $(0.45)$ & $(0.46)$ & $(0.49)$ & $(0.43)$ & $(0.45)$ \\
\hline \multirow[t]{2}{*}{ Car $($ owner $=1)$} & 0.40 & 0.42 & 0.28 & 0.53 & 0.39 \\
\hline & $(0.49)$ & $(0.49)$ & $(0.45)$ & $(0.50)$ & $(0.49)$ \\
\hline \multirow[t]{2}{*}{ Home $($ owner $=1$ ) } & 0.14 & 0.14 & 0.10 & 0.18 & 0.11 \\
\hline & $(0.35)$ & $(0.34)$ & $(0.30)$ & $(0.38)$ & $(0.31)$ \\
\hline \multirow[t]{2}{*}{ Children under 7} & 0.89 & 0.86 & 0.99 & 0.73 & 0.94 \\
\hline & $(0.83)$ & $(0.81)$ & $(0.82)$ & $(0.76)$ & $(0.84)$ \\
\hline \multirow[t]{2}{*}{ Children under 19} & 0.91 & 0.91 & 0.88 & 0.94 & 0.88 \\
\hline & $(0.99)$ & $(0.97)$ & $(0.93)$ & $(0.98)$ & $(0.99)$ \\
\hline \multirow[t]{2}{*}{ Work experience (years) } & 10.99 & 11.25 & 9.30 & 12.56 & 10.93 \\
\hline & $(7.02)$ & $(7.44)$ & $(6.87)$ & $(7.85)$ & $(6.85)$ \\
\hline \multicolumn{6}{|l|}{ Schooling ( \% ) } \\
\hline \multirow[t]{2}{*}{ No high school } & 0.19 & 0.19 & 0.29 & 0.14 & 0.17 \\
\hline & $(0.39)$ & $(0.39)$ & $(0.45)$ & $(0.35)$ & $(0.37)$ \\
\hline \multirow[t]{2}{*}{ High school } & 0.13 & 0.14 & 0.17 & 0.12 & 0.14 \\
\hline & $(0.33)$ & $(0.35)$ & $(0.37)$ & $(0.33)$ & $(0.35)$ \\
\hline \multirow[t]{2}{*}{ Post-secondary } & 0.52 & 0.53 & 0.44 & 0.55 & 0.56 \\
\hline & $(0.50)$ & $(0.50)$ & $(0.50)$ & $(0.50)$ & $(0.50)$ \\
\hline \multirow[t]{2}{*}{ University } & 0.16 & 0.15 & 0.10 & 0.19 & 0.13 \\
\hline & $(0.37)$ & $(0.36)$ & $(0.30)$ & $(0.39)$ & $(0.33)$ \\
\hline Sample size & 970 & 997 & 253 & 445 & 299 \\
\hline
\end{tabular}

Interestingly, columns (3)-(5) shows important differences. Among the unqualified group fewer are married, own a car or a house, and more are foreign born. Most importantly, the overall level of schooling and the number of years of work experience are by far the lowest among the treatment subgroups. Those in the ineligible group are slightly older, proportionately more own a car or a house and have fewer preschoolers. They are by far the best educated group among the treatment subgroups ( $74 \%$ have some post-secondary schooling) and have the most years of experience at baseline. Finally, the overall characteristics of those who qualified are somewhat located between those of the two previous groups. They are better educated and

\footnotetext{
${ }^{13}$ According to the provincial welfare program, the net value of houses and cars are assumed to generate a monthly income flow that contributes to the household's income. Assets are thus implicitly means-tested.
} 
have more years of experience than the unqualified group but not so much as those in the ineligible group.

Table 2: Sample statistics: Mean labour market outcomes ${ }^{\dagger}$ (Standard errors between in parentheses.)

\begin{tabular}{|c|c|c|c|c|c|}
\hline & \multirow{3}{*}{$\begin{array}{c}\text { Control group } \\
(1)\end{array}$} & \multicolumn{4}{|c|}{ Treatment groups } \\
\hline & & All & Unqualified $^{\ddagger}$ & Ineligible & Qualified \\
\hline & & $(2)$ & $(3)$ & $(4)$ & $(5)$ \\
\hline \multirow[t]{2}{*}{ Hourly wage } & 10.05 & 9.71 & 9.42 & 10.94 & 8.65 \\
\hline & $(4.25)$ & $(4.03)$ & $(5.06)$ & $(4.41)$ & $(2.79)$ \\
\hline \multirow[t]{2}{*}{ Log-wage } & 2.21 & 2.19 & 2.13 & 2.30 & 2.11 \\
\hline & $(0.42)$ & $(0.38)$ & $(0.43)$ & $(0.43)$ & $(0.27)$ \\
\hline \multirow[t]{2}{*}{ Monthly hours } & 138.42 & 133.30 & 132.12 & 133.71 & 133.30 \\
\hline & $(38.50)$ & $(34.78)$ & $(36.01)$ & $(36.16)$ & $(33.01)$ \\
\hline \multirow[t]{2}{*}{ Monthly earnings } & 1366.22 & 1278.13 & 1177.14 & 1444.58 & 1153.96 \\
\hline & $(674.99)$ & $(592.67)$ & $(554.45)$ & $(672.83)$ & $(474.68)$ \\
\hline \multirow[t]{2}{*}{ Monthly log-earnings } & 7.07 & 7.01 & 6.93 & 7.12 & 6.94 \\
\hline & $(0.47)$ & $(0.45)$ & $(0.44)$ & $(0.50)$ & $(0.50)$ \\
\hline \multirow[t]{2}{*}{ Monthly SSP benefits } & & & & & 700.56 \\
\hline & & & & & $(215.37)$ \\
\hline
\end{tabular}

${ }^{\dagger}$ The means are computed over 72 months and exclude zero values. Wage rates and earnings are expressed in 1993 constant dollars.

${ }^{\ddagger}$ Very few unqualified treatments work during the sample period. Hence, we have to be careful with the interpretation of these means.

Table 2 is similar to Table 1 except that it focuses on labor market outcomes. The means are computed over the 72-month period of observation so that differences between the controls and treatments reflect behavioral adjustments. Interestingly, the mean hourly wage rates of the two groups are nearly identical. Yet, there is substantial variation within the treatment group. Indeed, the ineligible treatments earn an average wage rate that is $8.9 \%$ higher than the controls and as much as $26.5 \%$ higher than the qualified treatments. Assuming full-time employment (2000 hours), a qualified treatment could expect an income supplement of 10,100\$. An ineligible treatment, had she qualified, could only expect $7,810 \$$ on average. The differences in wage rates do not translate into large differences in (conditional) hours of work, as controls only work slightly more hours per month than the treatments and very little variation is observed among the treatment subgroups. Consequently, the variations in monthly earnings arise principally because of variations in the wage rates.

\subsection{Wage distributions}

The figures reported in Table 2 provide some crude evidence that the establishment of eligibility may be related to expected wage rates. To investigate the matter further, Figure 2 plots the 
hourly wage rates of the control and treatment groups for the duration of the experiment. ${ }^{14}$ As reported in Table 2, the hourly wage rates of the two groups are very similar when considered over the whole period. Yet closer inspection reveals that members of the treatment group who worked during the eligibility period were earning a higher wage than members of the control group (see bottom panel). On the other hand, they were accepting jobs offering lower pay at the end of the qualification phase and over the course of the entire entitlement phase. Such a pattern is consistent with a reservation wage strategy as discussed previously. Figure 3 is

Figure 2: Hourly wage rates, by group

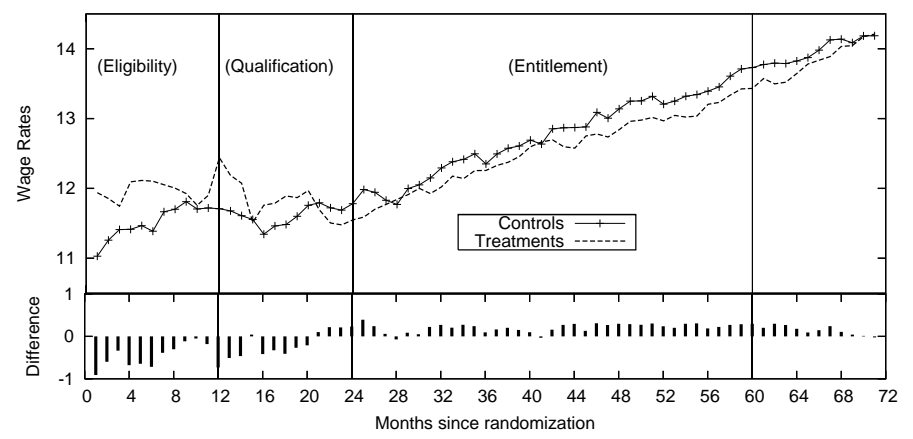

similar to Figure 2 but separates the members of the treatment group between those who left $I A$ before establishing eligibility and those who did not. The average difference between the average hourly wage rate of the two groups is $20.0 \%$ and nears $45 \%$ in the first few months of the qualification phase. ${ }^{15}$ Interestingly, the accepted wages among the qualified treatments increase significantly in the months just prior to the termination of the entitlement period and in the aftermath. In fact, the average accepted wage offers in months $65-72$ is identical to the average accepted wages of the control group. This pattern is also consistent with a reservation wage strategy.

To better appreciate the differences between the groups, Figure 4 depicts the kernelsmoothed density functions of log-wages for the control group and the three treatment subgroups. The wage rates are computed as the mean of all reported individual wages over the course of the experiment. The main notable feature of this figure is that the density functions of the qualified and unqualified treatments are heavily skewed to the left, while the density function of ineligible applicants has a very heavy tail to the right. The figure also shows that the density function of the controls more or less corresponds to a combination of the other three curves, as should be expected. This is consistent with Table 2 which showed that the average wage rates of the control and treatment groups are nearly identical. Figure 4 highlights the

\footnotetext{
${ }^{14}$ The figure is almost identical to the one reported by Card and Hyslop (2009) despite the fact that their sample differs slightly from ours.

${ }^{15}$ We do not report the average hourly wage rate for the qualified group in the eligibility phase as there are too few observations to compute reliable statistics.
} 
Figure 3: Hourly wage rates, by group

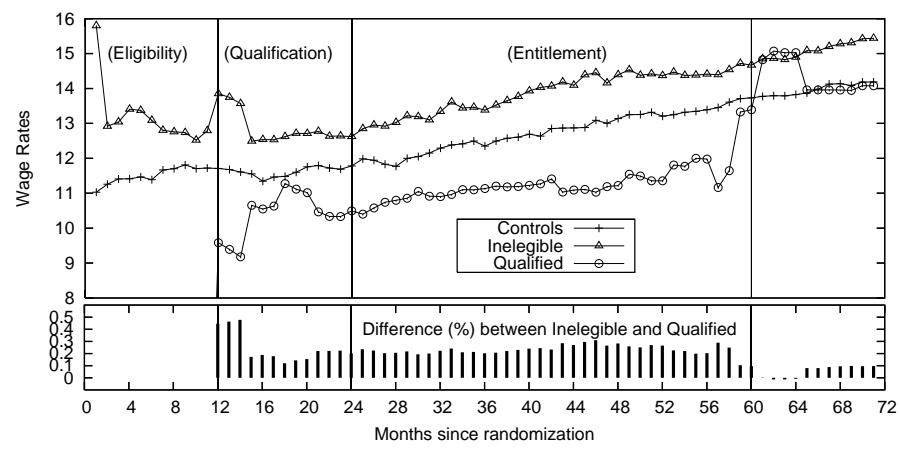

fact that there is considerable heterogeneity among the treatment subgroups. It also suggests that those who end-up receiving SSP benefits are precisely those who benefit the most from the program.

Figure 4: Kernel-smoothed densities of log-wages

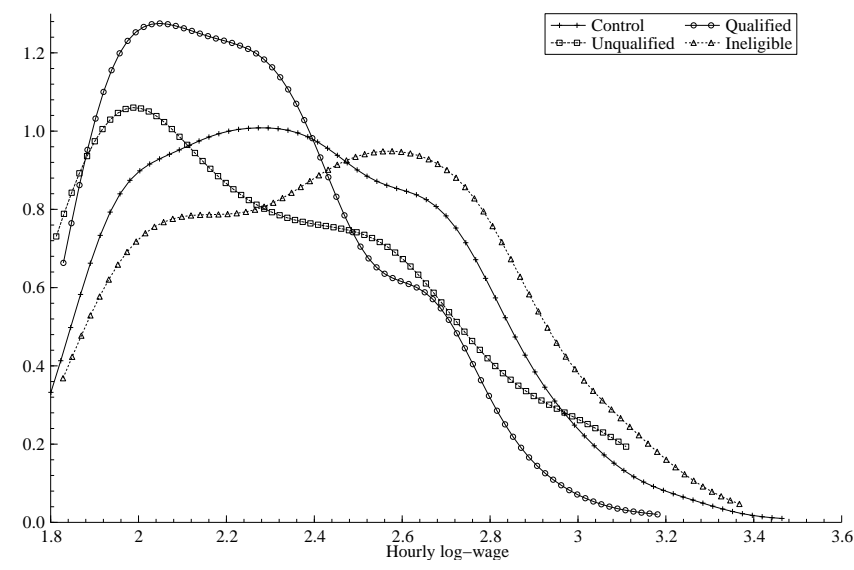

The preceding figure suggests that the SSP's built-in incentives may have resulted in sorting the treatments into various subgroups with different observable and presumably unobservable characteristics. While suggestive the figures provide no formal evidence that the differences they underline are statistically significant. Table 3 reports a series of tests of equality between the density functions of various outcomes. ${ }^{16}$ The test statistics are based on recent work by

\footnotetext{
${ }^{16}$ The distribution functions of the monthly hours of work and earnings are not reported for the sake of brevity but are available upon request.
} 
Li (1996). The first column of the table reports test results for various combinations of log-

Table 3: Equality of Distributions: Li's Statistics ${ }^{\dagger}$

(Bandwidth in parentheses)

\begin{tabular}{|c|c|c|c|c|c|}
\hline & Log-wages & \multicolumn{2}{|c|}{ Hours } & \multicolumn{2}{|c|}{ Log earnings } \\
\hline & Months & Months & Months & Months & Months \\
\hline & $1-72$ & $1-72$ & $61-72$ & $1-72$ & $61-72$ \\
\hline & (1) & $(2)$ & $(3)$ & $(4)$ & $(5)$ \\
\hline \multirow{2}{*}{ Qualified vs control } & 5.559 & 0.918 & 0.576 & 6.176 & 2.226 \\
\hline & $(0.096)^{\star}$ & $(7.363)$ & $(9.490)$ & $(0.127)^{\star}$ & $(0.153)^{\star}$ \\
\hline \multirow[t]{2}{*}{ Qualified vs ineligible } & 13.123 & 0.258 & -0.068 & 12.523 & 3.985 \\
\hline & $(0.096)^{\star}$ & $(7.363)$ & $(10.387)$ & $(0.127)^{\star}$ & $(0.175)^{\star}$ \\
\hline \multirow[t]{2}{*}{ Qualified vs unqualified } & 1.654 & 2.155 & 0.570 & 3.283 & 0.877 \\
\hline & $(0.096)^{\star \star}$ & $(7.363)^{\star}$ & $(11.324)$ & $(0.127)^{\star}$ & $(0.175)$ \\
\hline \multirow[t]{2}{*}{ Control vs unqualified } & 2.774 & 1.640 & -0.775 & 2.724 & 0.597 \\
\hline & $(0.097)^{\star}$ & $(8.495)$ & $(9.490)$ & $(0.136)^{\star}$ & $(0.153)$ \\
\hline \multirow[t]{2}{*}{ Control vs ineligible } & 1.714 & -0.767 & 0.214 & 1.422 & 1.854 \\
\hline & $(0.097)^{\star \star}$ & $(8.495)$ & $(9.490)$ & $(0.136)$ & $(0.153)^{\star \star}$ \\
\hline \multirow[t]{2}{*}{ Unqualified vs ineligible } & 4.222 & 1.547 & 0.182 & 5.077 & 3.947 \\
\hline & $(0.117)^{\star}$ & $(9.520)$ & (10.387) & $(0.179)^{\star}$ & $(0.186)^{\star}$ \\
\hline
\end{tabular}

${ }^{\dagger}$ The test compares $H_{0}: \hat{f}\left(x^{f}\right)=\hat{g}\left(x^{g}\right)$ to $H_{1}: \hat{f}\left(x^{f}\right) \neq \hat{g}\left(x^{g}\right)$. The test statistic is $\sim N(0,1)$.

Probability density functions are statistically different at 0.05 level $\left({ }^{\star}\right)$ and at 0.10 level $\left({ }^{\star \star}\right)$.

wage densities over the 72-month window. According to the table, all the distributions are distinct. Column (2) compares monthly hours of work over the same 72-months window while column (3) focuses on the year that followed the last month of SSP receipt (months 61 to 72). Interestingly, column (2) shows that the null assumption that the distributions are identical is only rejected when comparing qualified and unqualified treatments. Likewise, Column (3) concludes that the hours distribution are identical for all pairwise comparisons in the months that followed the end of the experiment. Columns (4) and (5) are similar to the two previous ones but focus on earnings instead. The earnings distributions combine monthly hours of work and hourly wage rates. Not surprisingly it is found that most distributions are different both over the 72-month window and in the year that followed the experiment.

\subsection{Participation in work}

Despite its generosity, only approximately $20 \%$ of all treatments benefit from the supplement in any given month. The figure rises to $70 \%$ among qualified treatments. On average, the latter received the supplement during only 26 months out of a maximum of 36 .

Figure 5 provides prima facie evidence of behavioural response to the SSP incentives. The top panel shows the response of the treatment group as a whole. The participation rates of the group members lie above those of the control group during the qualification and entitlement phases. They are also slightly above during the post-SSP period. The figure also provides weak evidence of delayed exit behaviour as the participation rates of the treatment group lie below those of the treatment group during the eligibility phase. 
The bottom panel of the figure plots the participation rates of the members of the treatment group according to their SSP status. The figure shows that the responses to the program exhibit considerable heterogeneity. As expected, the participation rates of qualified treatments is highest in the first few months of the entitlement phase. They decrease both during and past the entitlement phase but remains higher than that of the control group well past the end of the experiment. This result is similar to what has been found by others using slightly different samples [e.g. Card and Hyslop (2009)]. Nearly none of unqualified treatments report working during the eligibility phase. Their participation rates increase steadily at about the same rate as that of the members of the control group but always remain by far the lowest. Interestingly, the participation rates of the ineligible treatments are higher than those of the control group during the whole sample period and are almost identical to those of the qualified treatments in the post-entitlement phase. ${ }^{17}$

Figure 5: Monthly labour market participation rates

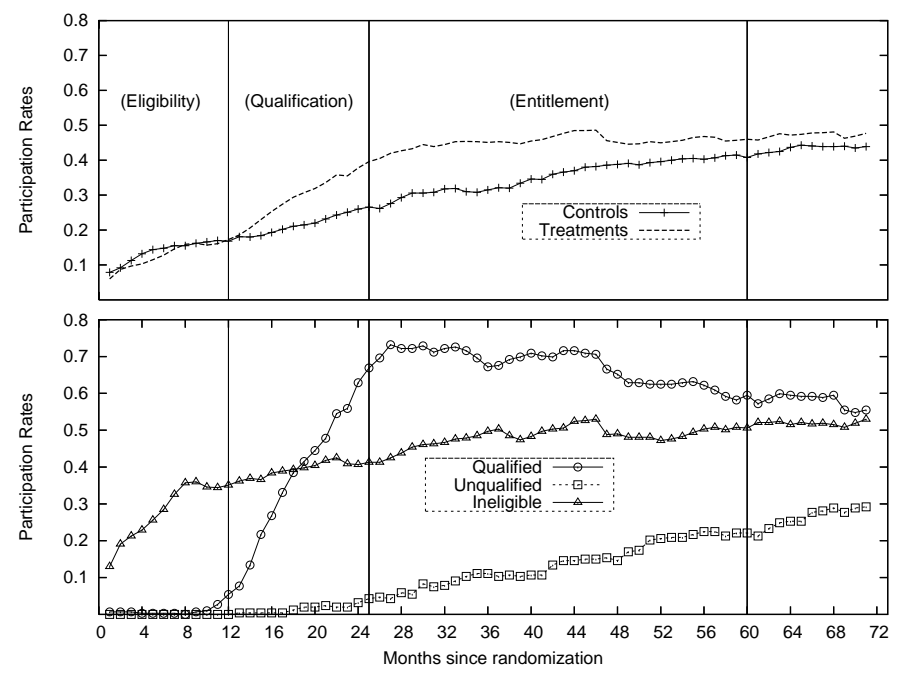

\section{Empirical specification}

The theoretical model and the empirical evidence of the previous sections have highlighted the fact that the establishment of eligibility may be correlated with expected wage rates. As argued in section 2 , these are potentially determined by unobserved individual effects. Likewise, the decision to leave $I A$ may also be affected by unobserved individual effects, irrespective of treatment status, that are correlated to those that determine the wage rates. Omission of these unobserved effects will likely lead to biased parameter estimates of the treatment effects.

\footnotetext{
${ }^{17}$ The participation rates in months $69-72$ are not statistically different at the $5 \%$ level of significance.
} 


\subsection{Average Treatment Model}

Our empirical strategy consists in estimating three different models with increasing degrees of sophistication. The first and simpler model focuses on the average treatment effect of the SSP experiment. The goal is to measure the expected behavioural impact for a member of the treatment group chose at random. This average treatment effect corresponds to the upper panel of Figure 5. The model focuses on the monthly transitions between $I A$ and work. Both states are assumed mutually exclusive and exhaustive. ${ }^{18}$ Let

$$
y_{i t}^{\star}=\mathbf{z}_{\mathbf{i t}} \delta+\alpha_{i}+\xi_{i t}
$$

be a latent variable measuring the (indirect) utility of working relative to $I A$, where $\mathbf{z}_{\mathbf{i t}}$ is a vector of exogenous variables, $\alpha_{i}$ is an unobserved individual effect, and $\xi_{i t}$ is a contemporaneous error term. The observable model is given by:

$$
y_{i t}=\left\{\begin{array}{lll}
1 & \text { if } \quad y_{i t}^{\star}>0 \\
0 & \text { if } \quad y_{i t}^{\star} \leq 0 .
\end{array}\right.
$$

The random effects are assumed to be iid $\sim N\left(0, \sigma_{\alpha}^{2}\right)$ while the contemporaneous terms are assumed to be iid $\sim N(0,1)$. This specification corresponds to a standard fixed effects probit model. The treatment effects are captured through a series a interactive variables between a treatment group dummy variable and months since randomization. Interaction variables are thus defined for each of the eligibility, qualification, entitlement and post-SSP phases.

\subsection{Treatment on the Treated Model - No Selection into Treatment}

The second model explicitly accounts for the eligibility and qualification statuses but does not take into account the selection process based on the wage rates. As with Model 1, it focuses on the monthly transitions between $I A$ and work and is based on equation (1). Recall that a treatment must have remained on $I A$ for the first 13 months following random assignment to be considered eligible. Conversely, an ineligible treatment is one who has left $I A$ for a full-time job within the first 13 months following random assignment. We thus define the eligibility status as follows:

$$
\text { Eligible }_{i t}= \begin{cases}1 & \text { for } 13<t \leq \min \left[T^{Q}, 25\right] \text { if } y_{i t}=0 \text { for } t=1, \ldots, 13 \\ 0 & \text { otherwise }\end{cases}
$$

\footnotetext{
${ }^{18}$ Welfare claimants are entitled to work a limited number of hours each month. As such $I A$ and work are not entirely exclusive states. We abstract from this possibility and consider the state to be $I A$ in a given month if the individual receives $I A$ benefits, irrespective of her working status. As argued by Card and Hyslop (2009),

"A limitation of our modeling approach is the narrow focus on welfare participation, rather than on a broader set of outcomes, such as welfare and employment status. Over most of the sample period the time profiles of experimental impacts on welfare participation and full-time employment are mirror images. Thus we believe that our basic findings can be translated directly into implications for employment".
} 
where $T^{Q}$ is the month in which the individual establishes qualification, if at all. Likewise, the ineligibility status is defined as:

$$
\text { Ineligible }_{i t}=\left\{\begin{array}{l}
1 \quad \text { for } T^{I}<t \leq 71 \quad \text { if } y_{i T^{I}}=1 \text { with } 1 \leq T^{I} \leq 13 \\
0 \quad \text { otherwise. }
\end{array}\right.
$$

Thus a treatment who is observed working full-time at month $T^{I}$ prior to month 13 becomes ineligible as of $T^{I}$ and remains so for the remainder of the experiment. ${ }^{19}$ Finally, a qualified treatment is one who has found a job at month $T^{Q} \leq 25$. SSP entitlement is thus defined as:

$$
\operatorname{SSP}_{i t}= \begin{cases}1 & \text { for } T^{Q}<t \leq\left(T^{Q}+35\right) \\ 0 & \text { otherwise }\end{cases}
$$

We also define two additional dummy variables to capture behavioural adjustments once eligibility and entitlement statuses expire. First, an unqualified treatment is one who has established eligibility but who did not find a job during the qualification phase, i.e.

$$
\text { Unqualified }_{i t}=\left\{\begin{array}{ll}
1 & \text { for } 25<t \leq 71 \\
0 & \text { otherwise }
\end{array} \quad \text { if } \text { Eligible }_{i 25}=1\right.
$$

A qualified treatment may change his behaviour once the entitlement period is over. To capture this we define the following dummy variable:

$$
\operatorname{PostSSP}_{i t}= \begin{cases}1 & \text { for }\left(T^{Q}+35\right)<t \leq 71 \\ 0 & \text { otherwise }\end{cases}
$$

The treatment variables, Eligible $i t$, Ineligible $i t, \mathrm{SSP}_{i t}$, Unqualified ${ }_{i t}$, and PostSSP $_{i t}$, track the status of individual $i$ at month $t$ according to his participation history. Various combinations can be observed. Thus an ineligible individual remains so for the whole sample window. On the other hand, an eligible individual may become qualified or not depending on whether she managed to find a job during the qualification phase. In the event she was unsuccessful, the eligible treatment is turned off once the phase terminates and the unqualified variable is turned on. If successful the eligible treatment is turned off and the qualified treatment turned on in the month that follows the exit from $I A$. The treatment variables as defined above are thus mutually exclusive.

\footnotetext{
${ }^{19}$ In fact the dummy variables are set equal to one in the month that follows the establishment of a given status. Thus, for example, the eligibility status is set to zero from months 1 to 13 and set to one as of month 14 if the individual remained on the rolls without interruption.
} 


\subsection{Treatment on the Treated Model - Selection into Treatment}

The third model is similar to Model 2 except that it allows for selection into treatment. In addition to the participation equation $(1)$, the $(\log )$ wage equation is specified as

$$
\omega_{i t}=\mathbf{x}_{\mathbf{i t}} \beta+\eta_{i}+\zeta_{i t},
$$

where $\mathbf{x}_{\mathbf{i t}}$ is a vector of exogenous variables, $\eta_{i}$ is an individual (unobserved) effect, and $\zeta_{i t}$ is a contemporaneous error term. In order to identify the model we must make a number of assumptions about the stochastic structure. First, we assume that the contemporaneous error terms and the individual fixed effects are not correlated within and across equations (1) and $(2)$ :

$$
\operatorname{cov}\left(\xi_{i t}, \alpha_{i}\right)=\operatorname{cov}\left(\xi_{i t}, \eta_{i}\right)=\operatorname{cov}\left(\zeta_{i t}, \alpha_{i}\right)=\operatorname{cov}\left(\zeta_{i t}, \eta_{i}\right)=0 \quad \forall t
$$

To be consistent with the theoretical model, we assume that the unobserved heterogeneity terms are correlated:

$$
\left(\begin{array}{c}
\alpha_{i} \\
\eta_{i}
\end{array}\right) \sim N\left[\left(\begin{array}{l}
0 \\
0
\end{array}\right),\left(\begin{array}{cc}
\sigma_{\alpha}^{2} & \sigma_{\alpha \eta} \\
\sigma_{\alpha \eta} & \sigma_{\eta}^{2}
\end{array}\right)\right]
$$

Likewise, the error terms $\xi_{i t}$ and $\zeta_{i t}$ are also assumed to be correlated:

$$
\left(\begin{array}{c}
\xi_{i t} \\
\zeta_{i t}
\end{array}\right) \sim N\left[\left(\begin{array}{c}
0 \\
0
\end{array}\right),\left(\begin{array}{cc}
\sigma_{\xi}^{2} & \sigma_{\xi \zeta} \\
\sigma_{\zeta \xi} & \sigma_{\zeta}^{2}
\end{array}\right)\right] .
$$

A priori we expect the covariance $\sigma_{\alpha \eta}$ to be positive because high-productivity individuals (large $\eta_{i}$ ) probably have a greater attachment to the labor market (large $\alpha_{i}$ ). Conditional on $\eta_{i}$ and $\alpha_{i}, \sigma_{\xi \zeta}$ may capture the correlation between aggregate demand and supply shocks on wages and employment. It is thus difficult to sign $\sigma_{\xi \zeta}$ a priori. All the parameters are identified save for the variance of the latent equation (1) which we set to one $\left(\sigma_{\xi}^{2}=1\right)$.

\subsection{Likelihood Function}

Models 1 and 2 are simple fixed effects probit models. Model 3 is more complex. The likelihood function is based on the fact that the sample at our disposal can be divided into three separate parts. ${ }^{20}$ The first regime is composed of all those who work full-time in a given month and whose wage rates are observed. The probability of this occurring is given by:

$$
P_{i t}\left(R_{1} \mid \alpha_{i}, \eta_{i}\right)=\int_{-a}^{+\infty} g\left(\xi_{i t}, \zeta_{i t} \mid \alpha_{i}, \eta_{i}\right) \mathrm{d} \xi_{i t}
$$

\footnotetext{
${ }^{20}$ The sample comprises 1,957 individuals. We removed 10 eligible treatment who have worked during qualification but did not receive SSP benefits. Each individual is observed for 71 months. Thus there are 138,947 contributions to the likelihood function. The three regimes account for 43,304, 3,953 and 91,690 contributions, respectively.
} 


$$
\begin{aligned}
& =\int_{-a}^{+\infty} f\left(\zeta_{i t} \mid \alpha_{i}, \eta_{i}\right) f\left(\xi_{i t} \mid \zeta_{i t}, \alpha_{i}, \eta_{i}\right) \mathrm{d} \xi_{i t} \\
& =\frac{1}{\sigma_{\zeta}} \phi\left(\frac{\zeta_{i t}}{\sigma_{\zeta}} \mid \alpha_{i}, \eta_{i}\right) \Phi\left(\frac{a+\rho \zeta_{i t}}{\sqrt{1-\rho^{2}}} \mid \alpha_{i}, \eta_{i}\right),
\end{aligned}
$$

where $a=\mathbf{z}_{\mathbf{i t}} \delta+\alpha_{i}, \rho=\sigma_{\zeta \xi} / \sigma_{\zeta}$ is the correlation between $\zeta_{i t}$ and $\xi_{i t}, g$ is the bivariate normal density, $f$ is the univariate normal density, $\phi$ is the standard normal density and $\Phi$ is the normal cumulative distribution. The second regime refers to those who work in a given month but whose wage rates are not reported:

$$
\begin{aligned}
P_{i t}\left(R_{2} \mid \alpha_{i}, \eta_{i}\right) & =\int_{-a}^{+\infty} \int_{-\infty}^{+\infty} g\left(\xi_{i t}, \zeta_{i t} \mid \alpha_{i}, \eta_{i}\right) \mathrm{d} \zeta_{i t} \mathrm{~d} \xi_{i t} \\
& =\int_{-a}^{+\infty} f\left(\xi_{i t} \mid \alpha_{i}, \eta_{i}\right) \mathrm{d} \xi_{i t}=\Phi\left(a \mid \alpha_{i}, \eta_{i}\right) .
\end{aligned}
$$

Finally, the last regime relates to those who do not work in a given month:

$$
\begin{aligned}
P_{i t}\left(R_{3} \mid \alpha_{i}, \eta_{i}\right) & =\int_{-\infty}^{-a} \int_{-\infty}^{+\infty} g\left(\xi_{i t}, \zeta_{i t} \mid \alpha_{i}, \eta_{i}\right) \mathrm{d} \zeta_{i t} \mathrm{~d} \xi_{i t} \\
& =\int_{-\infty}^{-a} f\left(\xi_{i t} \mid \alpha_{i}, \eta_{i}\right) \mathrm{d} \xi_{i t}=\Phi\left(-a \mid \alpha_{i}, \eta_{i}\right)
\end{aligned}
$$

By integrating over the whole domain of $\xi_{i t}$ we implicitly assume that those who do not work in a given month did not receive a job offer. The unconditional likelihood function of our sample is obtained by integrating out the unobserved heterogeneity terms:

$$
\log L\left(\mathbf{x}_{\mathbf{i t}}, \mathbf{z}_{\mathbf{i t}} ; \delta, \beta, \Sigma\right)=\sum_{i=1}^{N} \log \int_{\alpha_{i}} \int_{\eta_{i}} \prod_{t=1}^{T} \prod_{j=1}^{J}\left[P_{i t}\left(R_{j} \mid \alpha_{i}, \eta_{i}\right)\right]^{I\left(R_{j}\right)} g\left(\alpha_{i}, \eta_{i}\right) \mathrm{d} \alpha_{i} \mathrm{~d} \eta_{i},
$$

where $N=1957, T=71, J=3$. The matrix $\Sigma$ includes all identified parameters in (3) and (4). Finally, $\mathbb{I}\left(R_{j}\right)$ is an index function equal to 1 if regime $j$ is chosen, 0 otherwise, and $P_{i t}\left(R_{j} \mid \alpha_{i}, \eta_{i}\right)$ is one of (5), (6) or (7). The parameter estimates are obtained by the method of simulated maximum likelihood [see e.g. Train (2003)]. ${ }^{21}$

\section{Results}

The three specifications we estimate include numerous parameters. These are spread over Tables $4-7$ to ease comparisons across models. Table 4 focuses on the impact of the demographic variables on employment. The parameter estimates of all three models are relatively

\footnotetext{
${ }^{21}$ The distribution $g\left(\alpha_{i}, \eta_{i}\right)$ is approximated by 500 Halton draws.
} 
similar qualitatively and all have the expected sign. The education variables need be interpreted relatively to high-school. Not surprisingly, more schooling is strongly associated with higher transition rates into employment. Likewise, more work experience and owning a car or a house at baseline is also associated with a higher participation rate. ${ }^{22}$ As expected, households with more preschoolers and teenagers are less likely to work. Interestingly, only Model 1 finds that women are less likely to work than men. Employment is found to be seasonal, being lowest in the Winter and highest in the Fall. Dummy variables are used to proxy the yearly fluctuations in the business cycle. The parameter estimates show that the two years during which the experimental sample was recruited (1994 and 1995) are those during which finding a job was hardest. After 1996, it appears as tough IA recipients had an easier time finding a job despite the fact that unemployment rates was not lower and that women's employment rates were stable between 1994 and $2000 .{ }^{23,24}$ In fact, higher participation rates may partly be explained by the tightening of $I A$ requirements that were introduced by the government of British Columbia in 1996. Finally, it is found that employment depicts considerable state dependence. Being employed in the previous month significantly increases the probability of employment in the current month.

\section{Average Treatment Effect (Model 1)}

Table 5 reports the parameter estimates of the treatment effects. Recall that the theoretical model stressed that members of the treatment group could be induced to delay their exit from $I A$ in order to establish eligibility. As shown in the lower panel, all three treatment effects in the eligibility phase are indeed negative. During the qualification phase (months 13-24), treatments have a lower probability of working in the first quarter but a larger one in the following two quarters. These results are also consistent with our theoretical discussion: As the qualification phase ends, treatments will lower their reservation wage in order to qualify for SSP benefits. Finally, between months 25 and 60, which corresponds to the entitlement phase, treatments are found to have significantly higher participation rates. Once the experiment has ended (months 60+), both groups appear to behave similarly because the treatment effects are not statistically different from zero. This result contrasts with those of Card and Hyslop (2009) who found the program to have had a positive but declining effect on employment past the entitlement phase.

Figure 6 plots the predicted participation of both the control and treatment groups. Although not shown, the model mimics the observed participation rates relatively well. The lower panel of the figure reports the difference in participation rates between the two groups on a monthly basis. Treatments have a monthly participation rate that is about 2 percentage

\footnotetext{
${ }^{22}$ The latter two variables may potentially be endogenous. We did investigate this issue by removing the two variables from the regression. The remaining parameter estimates were found to be very robust to their inclusion or exclusion.

${ }^{23}$ Unemployment rates in the Vancouver area were $8.6 \%, 7.9 \%, 7.9 \%, 8.2 \%, 8.0 \%, 7.7 \%$ and $5.8 \%$ for 1994 to 2000 respectively. Source: Statistics Canada, Table 282-0091.

${ }^{24}$ Ford et al. (2003), page 11.
} 
points lower than that of the controls in the eligibility phase. This is very close to the estimates reported in Card and Hyslop (2009) and Kamionka and Lacroix (2009) and supports the idea that the members of the treatment group do, to some extent, delay their exit from $I A$ in order to establish eligibility.

Figure 6: Predicted Participation Rates - Model 1

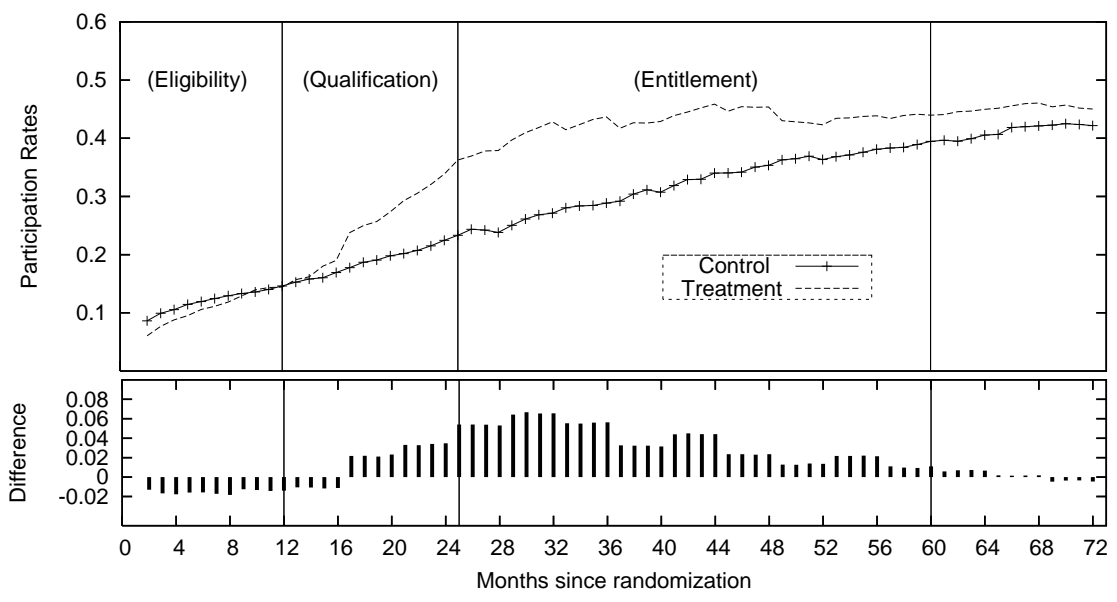

During the qualification phase, treatments have marginally lower participation rates in the first quarter and marginally higher rates in the next two quarters. Over the entitlement phase treatments have a relatively flat participation profile while controls have an upward-sloping one. Consequently, the average treatment effect decreases from its peak at the onset of the entitlement phase to close to zero at the end of the phase.

\section{Treatment Effects on the Treated - No Selection (Model 2)}

The second column of Table 5 relates to Model 2. The regression includes dummy variables for the eligibility, unqualified, ineligibility and entitlement statuses. Hence the parameter estimates need to be interpreted relative to the control group. To ease interpretation, the table is arranged in accordance with the SSP phases.

During the eligibility phase only treatments who voluntarily chose to forego future SSP benefits leave $I A$. On average their exit rates are found to be higher than those of the control group. The qualification phase contains four parameter estimates. The "Eligible" variable is an interactive variable equal to one each month a treatment remains on $I A$, conditional on not having left $I A$ once in the eligibility phase. As soon as a treatment finds a full-time job, 
the "Eligible" variable becomes equal to zero and the appropriate "Qualified $\times$ Month" variable is switched on. ${ }^{25}$ The parameter estimates indicate that treatments who have found a job in the 12-18 month period nevertheless have a lower average exit rate than members of the control group. ${ }^{26}$ In the last part of the qualification phase, treatments exit $I A$ at a faster rate than controls, presumably by lowering their wage requirements (see Figure 3 ) ${ }^{27}$ The ineligible indicator variable measures the relative probability of participation of those who have left $I A$ during the eligibility phase. As in the previous phase, their participation rates are still higher than those of the control group.

The parameter estimates of the treatment effects relative to the entitlement and postentitlement phases are next presented in the table. Recall that once the qualification ends, those who were unable to find a full-time job are now classified as "Unqualified". According to the parameter estimates they systematically have lower participation rates than the controls over the whole sample period. On the other hand, those who managed to qualify have much higher participation rates both during and after the entitlement phase. The gap between their participation rates and those of the control group slowly tapers off once the phase has ended, as shown by the parameter estimate of "Qualified $\times$ Trend". Finally, the ineligible group, those who have left the rolls prior to establishing eligibility, also have much higher participation rates than the controls, save for the post-entlitlement period. The parameter estimates are all positive and statistically significant but tend to decrease almost linearly in time.

\section{Treatment Effects on the Treated - Selection into SSP (Model 3)}

The parameter estimates of the third column of Table 5 relate to Model 3. Qualitatively, the parameters of Models 2 and 3 are relatively similar. Yet the parameters associated with the "Unqualified" variables in Model 3 are larger in absolute value. Those associated with the "Qualified" variables differ substantially in the qualification phase while those associated with the "Ineligible" variables are also slightly larger in Model 3. These differences, while apparently small, may nevertheless imply somewhat different participation dynamics.

Table 6 reports the average marginal treatment effects on employment over the entitlement phase. These are computed for all the treatments when using the parameter estimates of Model 1 but focus on the qualified subgroup when using the parameter estimates of Models 2 and 3. These average marginal treatment effects are calculated conditional on being on or off the labour market in the previous month. The table shows that, conditional on being employed in the previous month, Model 1 predicts that a member of the treatment group has

\footnotetext{
${ }^{25}$ Recall that the dummy variables change values in the month that follows a transition on the labour market, not in the concurrent month.

${ }^{26}$ During the first six months of the qualification phase, 122 treatments manage to find a full-time job. A third of them remained employed for one or two months only. The average duration of the employment spells was 3.5 months.

${ }^{27}$ In the last six months of the qualification phase, the average duration of the employment spells was 2.9 months.
} 
a probability of being employed in the current month that is approximately 4-5 percentage points greater than that of a member of the control group. If unemployed in the previous month, the model predicts that the treatment effects are essentially zero. Models 2 and 3 yield very similar predictions. Conditional on working in the previous month, they both imply an average treatment effect of between 6 and 12 percentage points. If unemployed in the previous month, they still predict an average treatment effect that ranges between 1 and 4 percentage points.

The average treatments effects of Models 2 and 3 for the entitlement period are very similar to those reported by Card and Hyslop (2009). To better understand the implicit participation dynamics of Models 2 and 3, and the role played by unobserved heterogeneity, we start by plotting the predicted monthly participation rates of Model 3 against the observed rates in Figures 7(a) and 7(b). Figure 7(a) focuses on qualified treatments while Figure 7(b) focuses on the control group. In both cases, the model matches the observed rates relatively well. The main discrepancies in Figure 7(a) occur in the qualification. The model tends to underestimate the participation rates by a few percentage points in some cases and by over 10 percentages points in some other cases. On the other hand, the model fits the participation dynamics very well in the entitlement and post-entitlement phases. In Figure 7(b) the main differences occur in the eligibility phase. Indeed, the model underestimates the participation rates of the control sample by a few percentage points. Just as for qualified treatments, the model does a reasonable job at predicting participation in the other phases.

Figure 7: Predicted Participation Rates - Model 3

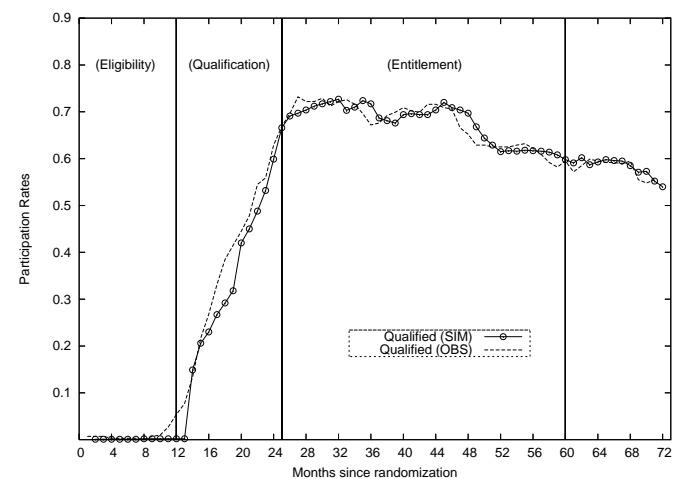

(a) Qualified treatments

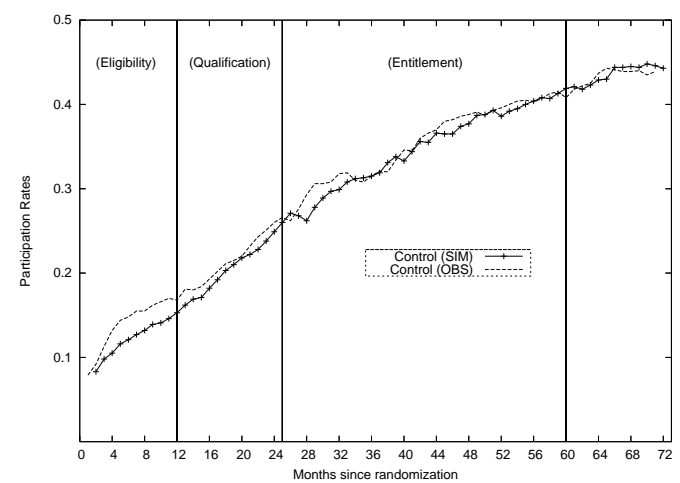

(b) Control group

The differences between the predictions of Models 2 and 3 are reported in Figure 8. Each line represents the difference between the predictions of Models 3 and 2, respectively. The top panel plots de differences separately for qualified treatments and controls. Recall from 
the previous figure that Model 3 underestimates the participation rates of the control group in the eligibility phase. According to Figure 8, Model 2 does yet a poorer job at predicting the control group's behaviour because the difference between the two models is positive. It systematically underestimates their participation rates by 1 to 2 percentage points over the whole sample period. The top panel also shows that there are important differences with respect to qualified treatments. Over the eligibility phase, both models yield nearly identical predictions. Important discrepancies occur over the qualification phase. There Model 3, despite underestimating the true participation rates, predicts higher participation rates than Model 2. Furthermore, the difference between the two models increase as the qualification phases nears the end. In other words, Model 3 better captures the incentive effect associated with finding a full-time job and securing entitlement for the next 36 months. During the entitlement and postSSP phases, Model 3 yields higher participation rates that better reflect observed behaviour. The bottom panel plots the difference between the two curves of the top panel. To the extent Model 3 is the preferred specification and is deemed bias-free, the distance between the two curves provides a crude estimate of the bias that is implicit in Model 2. The bias, while not very large, is systematic and varies monthly between 0 and 2 percentage points.

Figure 8: Differences in Participation Rates Between Models 2 \& 3

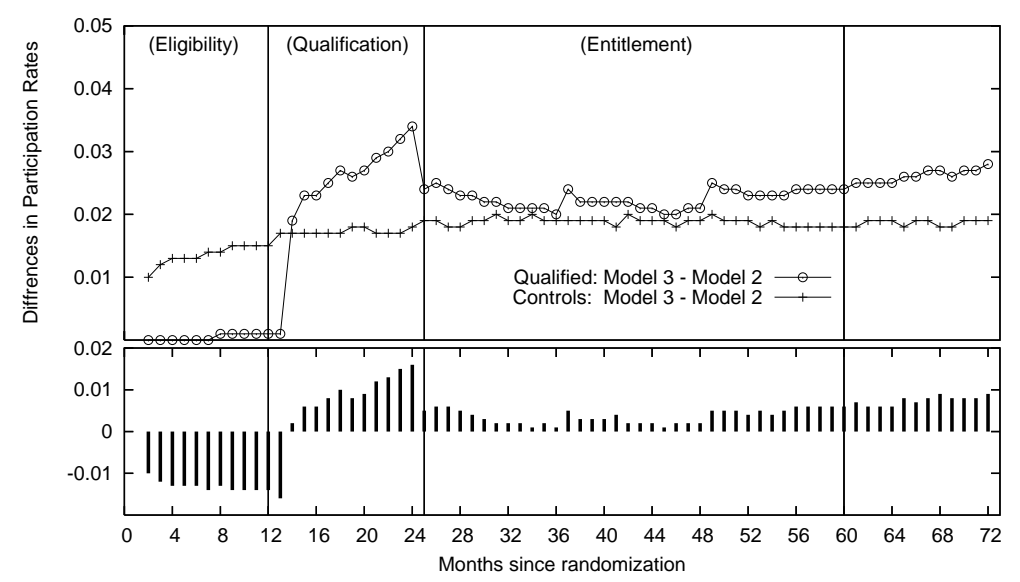

The difference between the two models hinges solely on the correlation between the wage and the participation equations. Table 7 reports the parameter estimates of the wage equation as well as the estimates of the ancillary parameters. Most parameter estimates have the expected sign and magnitude. Hence, more schooling and experience is conducive to a higher 
wage rate. ${ }^{28}$ Interestingly, unqualified treatments command the lowest monthly wage rate and is between $5.2 \%$ and $17.9 \%$ lower than the wage received by the control group. Qualified treatments also receive a much lower wage. During the entitlement phase, their wage rate is roughly $15.2 \%$ lower. This is consistent with the theoretical model that showed that SSP benefits could result in lower reservation wages. Furthermore, in the post-SSP they still command a relatively smaller hourly wage rate. The parameter estimates also indicate that the wages received by the ineligible treatments are higher and tend to increase over the sample window.

The parameters of the unobserved heterogeneity tell an interesting story. The standard error of the distribution is largest in Model $1\left(\sigma_{\alpha}=0.811\right)$, much smaller in Model $2\left(\sigma_{\alpha}=\right.$ $0.414)$ and nearly disappears in Model $3\left(\sigma_{\alpha}=0.024\right)$. In the latter case, the standard error of the unobserved heterogeneity in the wage equation is larger $\left(\sigma_{\eta}=0.099\right)$ and both components are highly correlated as expected. Thus an individual with strong preferences for work (high $\left.\alpha_{i}\right)$ is also likely to have higher than average productivity (high $\eta_{i}$ ). Yet, the correlation between the contemporaneous error terms is negative and highly statistically significant $\left(\rho_{\zeta \xi}=-0.15\right)$. On average, then, a high $\zeta_{i t}$ is associated with a low $\xi_{i t}$. This negative relation can result from the incentive effects brought about by the SSP program. Indeed, in any given month, more individuals with a low wage rate are found working once we condition for their observed and unobserved characteristics. This over-representation very likely results from the fact that the SSP pay-off is relatively more generous for low-wage workers.

All in all, our empirical findings concur with the theoretical model presented in Section 2. The built-in incentives of the SSP program induce recipients to self-select into eligibility and qualification. Consequently, those who end-up receiving SSP benefits are not representative of the population of welfare recipients. They have lower expected wage rates and less human capital than recipients who exit $I A$ prior to establishing eligibility. On the other hand, those who establish eligibility but never qualify have the lowest level of human capital and probably have weaker preferences for work according to the parameter estimates. By neglecting the selectivity into the program, Model 2 produces biased estimates the participation equation. The parameter estimates of both the demographic variables and the treatment effects differ in some cases substantially from those of Model 3. Thus the treatment effect measured under Model 2 is slightly underestimated because it omits the fact that qualified treatments with low wage rates have a strong incentive to join the labour market. Once we account for individual fixed effects and correlation between wages and participation this bias presumably washes away.

${ }^{28}$ Experience is time dependent. It is computed as follows:

$$
\text { Experience }_{i t}=\text { Experience }_{i 0}+\sum_{l=1}^{t-1} y_{i l}
$$

where Experience $_{i 0}$ is the number of months of experience at baseline. 


\section{Conclusion}

The Applicant Study of the Self-Sufficiency Project aimed at measuring the responsiveness of welfare applicants to a generous and time-limited income supplement. Randomly selected applicants had to meet two conditions to receive the supplement. The first, the eligibility condition, required that they remained on welfare for at least twelve months. The second, the qualification condition, required that they find a full-time job within twelve months after establishing eligibility and left the rolls.

The SSP demonstration has received widespread attention partly because of the generosity of the supplement it offered and partly because of the large behavioral responses it generated. Most papers that assess the impact of the SSP nevertheless neglect one important feature of the program, namely that the financial reward for becoming qualified is inversely proportional to the expected wage rate. In this paper we acknowledge the fact that the "treatment" is not homogeneous but is a continuum that depends on potential wage rates. Using a searchtheoretical framework, and under very simple assumptions about the wage distribution, we show that those who have a low expected wage rate have a clear incentive to establish eligibility. Consequently, those who eventually receive the SSP supplement may constitute a highly selected group among the treatment group.

Empirical non-parametric evidence strongly suggests that treatments self-select into eligibility. We thus specify an econometric model that simultaneously estimates the choice of working full time and the level of individual wage rates. The two equations are correlated through individual effects and through contemporaneous shocks. We find mild evidence that treatments self-select into eligibility and qualification. Once we properly account for the selection issue, the treatment effects increase slightly and remain important. 


\section{References}

Berlin, G., W. Bancroft, D. Card, W. Lin, and P. K. Robins (1998) 'Do work incentives have unintended consequences ? measuring entry effects in the self-sufficiency project.' Working Paper, SRDC

Bitler, M.P., J.B. Gelbach, and H.W. Hoynes (2006) 'Distributional impacts of the Self-Sufficiency Project.' SRDC Working Paper 06-01

Bloemen, H.G. (1997) 'Job search theory, labour supply and unemployment duration.' Journal of Econometrics 79, 305-325

Bontemps, C., J.-M. Robin, and G.J. Van den Berg (1999) 'An empirical equilibrium job search model with search on the job and heterogeneous workers and firms.' International Economic Review 40(4), 1039-1074

Bowlus, Audra, Lance Lochner, Chris Robinson, and Yahong Zhong (2006) 'Human Capital and Search Behavior.' SRDC Working Paper 06-10

Card, D., and D.R. Hyslop (2005) 'Estimating the effects of a time-limited earnings subsidy for welfare leavers.' Econometrica

- (2009) 'The dynamic effects of an earnings subsidy for the long-term welfare recipients: Evidence from the self sufficiency project applicant experiment.' Forthcoming, Journal of Econometrics

Card, David, and Philip K. Robins (2005) "How important are "entry effects" in financial incentive programs for welfare recipients? Experimental evidence from the Self-Sufficiency Project.' Journal of Econometrics 125, 113-139

Dubin, Jeffrey A., and D. Rivers (1993) 'Experimental estimates of the impact of wage subsidies.' Journal of Econometrics 56, 219-242

Ford, Reuben, David Gyarmati, Kelly Foley, Doug Tattrie, and Liza Jimenez (2003) 'Can Work Incentives Pay for Themselves? Final Report on the Self-Sufficiency Project for Welfare Applicants.' Social Research and Demonstration Corporation, rapport final

Ham, J.C., and R.J. LaLonde (1996) 'The effect of sample selection and intitial conditions in duration models: Evidence from experimental data on training.' Econometrica 64(1), 175-205

Hansen, Jorgen (2006) 'The effects of human capital and earnings supplements on income assistance dependence in Canada.' SRDC Working Paper 06-05

Kamionka, Thierry, and Guy Lacroix (2009) 'Assessing the External Validity of an Experimental Wage Subsidy.' Forthcoming, Annales d'Économie et de Statistique Li, Q. (1996) 'Nonparametric testing of closeness between two unknown distributions.' Econometric Reviews 15, 261-274

Mortensen, D.T. (1977) 'Unemplyment insurance and job search decisions.' Industrial and Labor Relations Review 30(4), 505-517

Postel-Vinay, F., and J.-M. Robin (2002) 'Equilibrium wage dsipersion with worker and employer heterogeneity.' Econometrica 70(6), 2295-2350

Stern, S., and J. Canals-Cerda (2002) 'Empirical search models.' In Search Theory and Unemployment, ed. Steven Woodbury and Carl Davidson (Kluwer Academic Publications) 
Train, Kenneth (2003) Discrete Choice Methods with Simulation (Cambridge University Press)

Wolpin, Kenneth, and Zvi Eckstein (1989) 'The specification and estimation of dynamic stochastic discrete choice models: A survey.' The Journal of Human Resources 24, 562-598 Zabel, Jeffrey, Saul Schwartz, and Stephen Donald (2004) 'An Econometric Analysis of the Impact of the Self-Sufficiency Project on Unemployment and Employment Durations.' Social Research and Demonstration Corporation, document de travail $\mathrm{n}^{o}$ 04-05 
Table 4: Participation equation: Demographic variables

\begin{tabular}{lrlrlrc}
\hline \hline Variables & \multicolumn{2}{c}{ Model 1 } & \multicolumn{2}{c}{ Model 2 } & \multicolumn{2}{c}{ Model 3 } \\
\hline & Para. & S.d. & Para. & S.d. & Para. & S.d. \\
\hline \hline Intercept & -1.748 & $(0.166)^{\star}$ & -2.123 & $(0.063)^{\star}$ & -2.090 & $(0.062)^{\star}$ \\
Less than high school & -0.292 & $(0.039)^{\star}$ & -0.092 & $(0.030)^{\star}$ & -0.113 & $(0.029)^{\star}$ \\
Post-secondary & -0.016 & $(0.027)$ & -0.009 & $(0.023)$ & 0.003 & $(0.022)$ \\
University & 0.064 & $(0.047)$ & 0.050 & $(0.027)^{\star \star}$ & 0.077 & $(0.026)^{\star}$ \\
Experience & 4.926 & $(0.328)^{\star}$ & 2.632 & $(0.141)^{\star}$ & 2.344 & $(0.116)^{\star}$ \\
Age & -3.281 & $(0.345)^{\star}$ & -1.762 & $(0.149)^{\star}$ & -1.513 & $(0.122)^{\star}$ \\
Car & 0.125 & $(0.012)^{\star}$ & 0.195 & $(0.014)^{\star}$ & 0.188 & $(0.013)^{\star}$ \\
Home & 0.042 & $(0.010)^{\star}$ & 0.102 & $(0.011)^{\star}$ & 0.117 & $(0.011)^{\star}$ \\
Children less that 7 years & -0.216 & $(0.012)^{\star}$ & -0.147 & $(0.010)^{\star}$ & -0.154 & $(0.010)^{\star}$ \\
Children 7-18 years & -0.085 & $(0.010)^{\star}$ & -0.036 & $(0.007)^{\star}$ & -0.034 & $(0.007)^{\star}$ \\
Married & 0.152 & $(0.019)^{\star}$ & 0.197 & $(0.018)^{\star}$ & 0.187 & $(0.018)^{\star}$ \\
Born in Canada (yes $=1)$ & 0.102 & $(0.048)^{\star}$ & 0.007 & $(0.016)$ & 0.013 & $(0.015)$ \\
Gender (woman $=1)$ & -0.010 & $(0.082)$ & 0.031 & $(0.023)$ & 0.016 & $(0.023)$ \\
Spring & 0.082 & $(0.020)^{\star}$ & 0.047 & $(0.018)^{\star}$ & 0.062 & $(0.018)^{\star}$ \\
Summer & 0.112 & $(0.018)^{\star}$ & 0.066 & $(0.018)^{\star}$ & 0.097 & $(0.018)^{\star}$ \\
Fall & 0.162 & $(0.021)^{\star}$ & 0.107 & $(0.019)^{\star}$ & 0.151 & $(0.019)^{\star}$ \\
1994 & -0.782 & $(0.027)^{\star}$ & -0.568 & $(0.035)^{\star}$ & -0.953 & $(0.032)^{\star}$ \\
1995 & -0.451 & $(0.021)^{\star}$ & -0.418 & $(0.024)^{\star}$ & -0.578 & $(0.023)^{\star}$ \\
1997 & 0.234 & $(0.021)^{\star}$ & 0.149 & $(0.023)^{\star}$ & 0.181 & $(0.023)^{\star}$ \\
1998 & 0.432 & $(0.022)^{\star}$ & 0.251 & $(0.026)^{\star}$ & 0.297 & $(0.025)^{\star}$ \\
1999 & 0.519 & $(0.023)^{\star}$ & 0.316 & $(0.027)^{\star}$ & 0.351 & $(0.027)^{\star}$ \\
2000-2001 & 0.653 & $(0.031)^{\star}$ & 0.382 & $(0.033)^{\star}$ & 0.433 & $(0.033)^{\star}$ \\
$y_{i t-1}$ & 3.105 & $(0.013)^{\star}$ & 3.190 & $(0.013)^{\star}$ & 3.173 & $(0.013)^{\star}$ \\
\hline \hline
\end{tabular}

${ }^{\star}$ P-value $\leq 0.05 . \quad{ }^{\star \star}$ P-value $\leq 0.10$ 
Table 5: Participation equation: Treatment effects

\begin{tabular}{|c|c|c|c|c|c|c|}
\hline \multirow[t]{2}{*}{ Variables } & \multicolumn{2}{|c|}{ Model 1} & \multicolumn{2}{|c|}{ Model 2} & \multicolumn{2}{|c|}{ Model 3} \\
\hline & Para. & S.d. & Para. & S.d. & Para. & S.d. \\
\hline \multicolumn{7}{|l|}{ Interaction variables } \\
\hline \multicolumn{7}{|l|}{ Eligibility PhaSe } \\
\hline Ineligible $\times$ Month 2-12 & \multicolumn{2}{|r|}{ - } & 0.627 & $(0.037)^{\star}$ & 0.910 & $(0.035)^{\star}$ \\
\hline \multicolumn{7}{|l|}{ Qualification Phase } \\
\hline Eligible & \multicolumn{2}{|r|}{ - } & -1.241 & $(0.066)^{\star}$ & -1.225 & $(0.066)^{\star}$ \\
\hline Qualified $\times$ Months $12-18$ & \multicolumn{2}{|r|}{ - } & -0.195 & $(0.047)^{\star}$ & -0.054 & $(0.045)^{\star}$ \\
\hline Qualified $\times$ Months $18-24$ & \multicolumn{2}{|r|}{ - } & 0.201 & $(0.047)^{\star}$ & 0.277 & $(0.046)^{\star}$ \\
\hline Ineligible $\times$ Months 12-24 & \multicolumn{2}{|r|}{ - } & 0.413 & $(0.033)^{\star}$ & 0.531 & $(0.032)^{\star}$ \\
\hline \multicolumn{7}{|l|}{ Entitlement Phase } \\
\hline Unqualified $\times$ Months 24 -36 & \multicolumn{2}{|r|}{ - } & -0.252 & $(0.064)^{\star}$ & -0.263 & $(0.060)^{\star}$ \\
\hline Unqualified $\times$ Months $36-48$ & \multicolumn{2}{|r|}{-} & -0.299 & $(0.055)^{\star}$ & -0.344 & $(0.052)^{\star}$ \\
\hline Unqualified $\times$ Months $48-60$ & \multicolumn{2}{|r|}{-} & -0.101 & $(0.056)^{\star}$ & -0.123 & $(0.054)^{\star}$ \\
\hline Qualified $\times$ Months $24-36$ & \multicolumn{2}{|r|}{-} & 0.533 & $(0.034)^{\star}$ & 0.549 & $(0.033)^{\star}$ \\
\hline Qualified $\times$ Months $36-48$ & \multicolumn{2}{|r|}{-} & 0.352 & $(0.036)^{\star}$ & 0.350 & $(0.035)^{\star}$ \\
\hline Qualified $\times$ Months $48-60$ & \multirow{2}{*}{\multicolumn{2}{|c|}{-}} & 0.226 & $(0.066)^{\star}$ & 0.246 & $(0.066)^{\star}$ \\
\hline Ineligible×Month 24-36 & & & 0.335 & $(0.035)^{\star}$ & 0.357 & $(0.034)^{\star}$ \\
\hline Ineligible $\times$ Month 36-48 & \multicolumn{2}{|r|}{-} & 0.186 & $(0.036)^{\star}$ & 0.198 & $(0.036)^{\star}$ \\
\hline Ineligible $\times$ Month 48-60 & \multicolumn{2}{|r|}{ - } & 0.086 & $(0.039)^{\star}$ & 0.098 & $(0.039)^{\star}$ \\
\hline \multicolumn{7}{|l|}{ POST-SSP PHASE } \\
\hline Unqualified $\times$ Months $60+$ & & - & -0.201 & $(0.055)^{\star}$ & -0.222 & $(0.052)^{\star}$ \\
\hline Qualified $\times$ Months $60+$ & & - & 0.219 & $(0.058)^{\star}$ & 0.222 & $(0.057)^{\star}$ \\
\hline Qualified $\times$ Trend & & - & -0.019 & $(0.004)^{\star}$ & -0.018 & $(0.004)^{\star}$ \\
\hline Ineligible $\times$ Month $60+$ & & - & 0.051 & $(0.041)$ & 0.046 & $(0.040)$ \\
\hline Interaction Variables & & & & & & \\
\hline ELIGIBILITY PHASE & & & & & & \\
\hline Months 2-4 & -0.259 & $(0.063)^{\star}$ & & - & & - \\
\hline Months 4-8 & -0.221 & $(0.056)^{\star}$ & & - & & - \\
\hline Months 8-12 & -0.157 & $(0.053)^{\star}$ & & - & & - \\
\hline QUALIFICATION PHASE & & & & & & \\
\hline Months $12-16$ & -0.129 & $(0.054)^{\star}$ & & - & & - \\
\hline Months 16-20 & 0.181 & $(0.052)^{\star}$ & & - & & - \\
\hline Months 20-24 & 0.263 & $(0.053)^{\star}$ & & - & & - \\
\hline ENTITLEMENT PHASE & & & & & & \\
\hline Months 24-28 & 0.403 & $(0.054)^{\star}$ & & - & & - \\
\hline Months 28-32 & 0.485 & $(0.056)^{\star}$ & & - & & - \\
\hline Months 32-36 & 0.413 & $(0.057)^{\star}$ & & - & & - \\
\hline Months $36-40$ & 0.257 & $(0.058)^{\star}$ & & - & & - \\
\hline Months $40-44$ & 0.357 & $(0.057)^{\star}$ & & - & & - \\
\hline Months $44-48$ & 0.175 & $(0.057)^{\star}$ & & - & & - \\
\hline Months 48-52 & 0.088 & $(0.057)$ & & - & & - \\
\hline Months 52-56 & 0.180 & $(0.060)^{\star}$ & & - & & - \\
\hline Months 56-60 & 0.101 & $(0.061)^{\star \star}$ & & - & & - \\
\hline POST-SSP PHASE & & & & & & \\
\hline Months 60-64 & 0.061 & $(0.059)$ & & - & & - \\
\hline Months $64-68$ & 0.026 & $(0.060)$ & & - & & - \\
\hline Months 68-72 & -0.027 & $(0.059)$ & & - & & - \\
\hline
\end{tabular}


Table 6: Average Marginal Treatment Effects: Entitlement Phase

\begin{tabular}{lcccccc}
\hline \hline Period & \multicolumn{3}{c}{ Model 1 } & \multicolumn{2}{c}{ Model 2 } & \multicolumn{2}{c}{ Model 3 } \\
\hline & $y_{t-1}$ & $y_{t-1}$ & $y_{t-1}$ & $y_{t-1}$ & $y_{t-1}$ & $y_{t-1}$ \\
& 1 & 0 & 1 & 0 & 1 & 0 \\
\cline { 2 - 7 } Months 24-28 & 0.036 & 0.007 & & & & \\
Months 28-32 & 0.051 & 0.012 & 0.120 & 0.041 & 0.112 & 0.041 \\
Months 32-36 & 0.059 & 0.015 & & & & \\
Months 36-40 & 0.051 & 0.012 & & & & \\
Months 40-44 & 0.031 & 0.006 & 0.083 & 0.022 & 0.078 & 0.022 \\
Months 44-48 & 0.043 & 0.009 & & & & \\
Months 48-52 & 0.023 & 0.004 & & & & \\
Months 52-56 & 0.013 & 0.002 & 0.056 & 0.013 & 0.057 & 0.014 \\
Months 56-60 & 0.022 & 0.004 & & & & \\
\hline \hline
\end{tabular}


Table 7: Wage equation

\begin{tabular}{|c|c|c|c|c|c|c|}
\hline \multirow[t]{2}{*}{ Variables } & \multicolumn{2}{|c|}{ Model 1} & \multicolumn{2}{|c|}{ Model 2} & \multicolumn{2}{|c|}{ Model 3 } \\
\hline & Para. & Std & Para. & Std & Para. & Std \\
\hline Intercept & & - & & 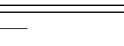 & 2.054 & $\overline{(0.019)^{\star}}$ \\
\hline Less than high school & & - & & - & 0.007 & $(0.022)$ \\
\hline Post-secondary & & - & & - & 0.218 & $(0.019)^{\star}$ \\
\hline University & & - & & - & 0.308 & $(0.020)^{\star}$ \\
\hline Experience & & - & & - & 2.600 & $(0.120)^{\star}$ \\
\hline Experience $^{2}$ & & - & & _ & -3.316 & $(0.207)^{\star}$ \\
\hline Exper. $\times$ LHS & & - & & - & -0.235 & $(0.117)^{\star}$ \\
\hline Exper $\times$ PostSec & & - & & - & -0.496 & $(0.097)^{\star}$ \\
\hline Exper. $\times$ Univ & & - & & - & -0.168 & $(0.105)$ \\
\hline \multicolumn{7}{|l|}{ Interaction Variables } \\
\hline \multicolumn{7}{|l|}{ ELIGIBILITY PHASE } \\
\hline Ineligible $\times$ Month 2-12 & & - & & - & 0.029 & $(0.014)^{\star}$ \\
\hline \multicolumn{7}{|l|}{ Qualification Phase } \\
\hline Qualified $\times$ Months $12-18$ & & - & & - & -0.166 & $(0.032)^{\star}$ \\
\hline Qualified $\times$ Months $18-24$ & & - & & - & -0.176 & $(0.022)^{\star}$ \\
\hline Ineligible $\times$ Month3 12-24 & & - & & - & -0.022 & $(0.009)^{\star}$ \\
\hline \multicolumn{7}{|l|}{ Entitlement Phase } \\
\hline Unqualified $\times$ Months $24-36$ & & - & & - & -0.173 & $(0.021)^{\star}$ \\
\hline Unqualified $\times$ Months $36-48$ & & - & & - & -0.063 & $(0.022)^{\star}$ \\
\hline Unqualified $\times$ Months $48-60$ & & - & & - & -0.065 & $(0.017)^{\star}$ \\
\hline Qualified $\times$ Months $24-36$ & & - & & - & -0.169 & $(0.011)^{\star}$ \\
\hline Qualified $\times$ Months $36-48$ & & - & & - & -0.134 & $(0.012)^{\star}$ \\
\hline Qualified $\times$ Months $48-60$ & & - & & - & -0.102 & $(0.018)^{\star}$ \\
\hline Ineligible $\times$ Month $24-36$ & & - & & - & 0.008 & $(0.009)$ \\
\hline Ineligible $\times$ Month $36-48$ & & - & & - & 0.055 & $(0.009)^{\star}$ \\
\hline Ineligible $\times$ Month 48-60 & & - & & - & 0.078 & $(0.009)^{\star}$ \\
\hline \multicolumn{7}{|l|}{ Post-SSP Phase } \\
\hline Unqualified $\times$ Months $60+$ & & - & & - & -0.054 & $(0.014)^{\star}$ \\
\hline Qualified × Months $60+$ & & - & & - & -0.078 & $(0.017)^{\star}$ \\
\hline Qualified $\times($ trend $)$ & & - & & - & 0.007 & $(0.001)^{\star}$ \\
\hline Ineligible $\times$ Month $60+$ & & - & & - & 0.103 & $(0.008)^{\star}$ \\
\hline \multicolumn{7}{|l|}{ Unobserved heterogeneity } \\
\hline$\sigma_{\alpha}$ & 0.811 & $(0.009)$ & 0.414 & $(0.010)$ & 0.024 & $(0.003)^{\star}$ \\
\hline$\sigma_{\eta}$ & & & & & 0.099 & $(0.033)^{\star}$ \\
\hline$\rho_{\alpha \eta}$ & & & & & 0.422 & $(0.211)^{\star}$ \\
\hline$\sigma_{\zeta}$ & & & & & 0.418 & $(0.001)^{\star}$ \\
\hline$\rho_{\zeta \xi}$ & & & & & -0.150 & $(0.012)^{\star}$ \\
\hline
\end{tabular}

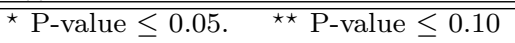

